\title{
An Examination of the Complex Pharmacological Properties of the Non-Selective Opioid Receptor Modulator Buprenorphine
}

\author{
Leana J. Pande ${ }^{1}$, Brian J. Piper ${ }^{1,2^{*}}$ \\ ${ }^{1}$ Department of Medical Education, Geisinger Commonwealth School of Medicine \\ ${ }^{2}$ Center for Pharmacy Innovation and Outcomes \\ * Brian J. Piper, Ph.D.525 Pine Street, Geisinger Commonwealth School of Medicine Scranton, PA 18411, USA
}

\begin{abstract}
Buprenorphine, an analogue of thebaine, is a Schedule III opioid in the United States used for opioid-use disorder and as an analgesic. Research has shown drugs like buprenorphine have a complicated pharmacology with characteristics that challenge traditional definitions of terms like agonist, antagonist, and efficacy. Buprenorphine has a high affinity for the mu (MOR), delta (DOR), kappa (KOR), and intermediate for the nociceptin opioid receptors (NOR). Buprenorphine is generally described as a partial MOR agonist with limited activity and decreased response at the mureceptor relative to full agonists. In opioid naïve patients, the drug's analgesic efficacy is equivalent to a full MOR agonist, despite decreased receptor occupancy and the "ceiling effect" produced from larger doses. Some argue buprenorphine's effects depend on the endpoint measured, as it functions as a partial agonist for respiratory depression, but a full-agonist for pain. Buprenorphine's active metabolite, norbuprenorphine, attenuates buprenorphine's analgesic effects due to NOR binding and respiratory depressant effects. The method of administration impacts efficacy and tolerance when administered for analgesia. There have been eleven-thousand reports involving buprenorphine and minors (age < 19$)$ to US poison control centers, the preponderance $(89.2 \%)$ with children. The consequences of prenatal buprenorphine exposure in experimental animals and humans should continue to be carefully evaluated. In conclusion, buprenorphine's characterization as only a partial mu-agonist is an oversimplification. Contemporary research shows the traditional explanation of the pharmacology of buprenorphine does not take into account changes to receptor theory, pharmacological terminology, route of administration, and biologically active major metabolites.
\end{abstract}

Keywords: opiate; mu; kappa; delta; nociceptin; addiction; overdose; prenatal; postnatal

\section{Introduction and history}

Buprenorphine was first derived from thebaine in 1966. Buprenorphine was characterized as a partial agonist at the mu-opioid receptor (MOR, 1). The Committee on Drug Addiction primarily focused on morphine and looked for a way to ensure its multitude of uses, without its addictive side effects in the 1920s. Buprenorphine was considered a part of the solution to the $20^{\text {th }}$ century opium problem. Its agonistantagonist pharmacological character was more fully characterized in 1972 and potential as an addiction treatment recognized in $1979(2,3)$. It is a semi-synthetic and lipophilic drug. It has activity at all four major opioid receptors: MOR, kappa (KOR), delta (DOR), and the nociceptin receptor (NOR). Of the four main opioid receptors, three (MOR, DOR, and KOR) were identified in the 1960s, and the opioid receptor like (ORL), currently and henceforth designated as the NOR, discovered in the 1990s (4). In addition to their involvement in nociception, KOR is widely expressed during prenatal and early postnatal periods including on progenitor, ependymal and neuronal cells (5) which raises the potential that a KOR antagonist like buprenorphine could have an adverse impact on brain development. This may also apply to other (MOR/NOR) opioid receptors which are important for myelination (6). The NOP is considered an atypical, low affinity receptor for opioid peptides (4). Although marketed for analgesia and addiction treatment, early research subjects reported that buprenorphine was the "most reinforcing drug they had ever used" (2). Injectable buprenorphine became commercially available in the US in 1981 (1). By 1985, it was available in twenty-nine countries (2). Buprenorphine was originally considered a Schedule V narcotic in the US until 2002 when, after three attempts by the Drug Enforcement Agency, it was rescheduled as Schedule III $(1,2)$. US sales of buprenorphine have increased substantially. Buprenorphine was the most commonly used opioid by US veterinarians (7). From 20072017, buprenorphine distribution increased seven-fold to US pharmacies and five-fold to hospitals. The US Medicaid program spent 1.1 billion on buprenorphine in 2017 alone (8) Pharmacy distribution increased by $30.7 \%$ and hospitals by $42.3 \%$ from 2017 to 2019 (Figure 1).

Although there have been many reviews about the pharmacological effects of buprenorphine $(2,9,10,11)$, examination of pharmacology educational materials $(12,13$, $15,16)$ revealed a very simplified MOR-centric presentation of this drug. Therefore, the goal of this review was to examine the pharmacodynamics as opioid neuropharmacology and therapeutics is an expanding field (17). Other topical and related areas including pharmacokinetics, misuse potential, toxicology, and possible prenatal sequelae were also reviewed. 


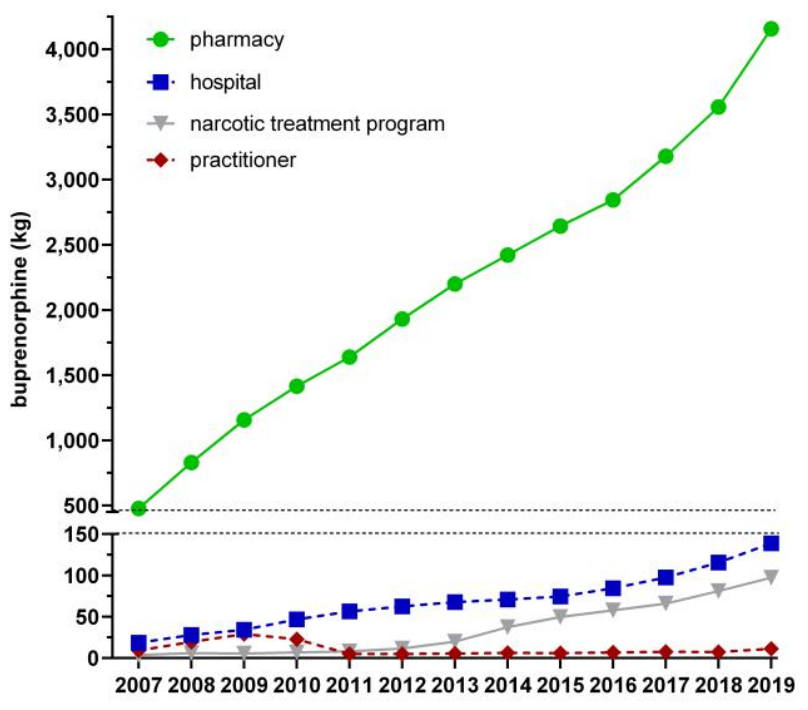

Figure 1. Distribution of buprenorphine by business activity as reported to the US Drug Enforcement Administration showeed a 8.7 fold increase to pharmacies and 7.5 fold increase to hospitals from 2007 to 2019.

\subsection{Pharmacokinetics and pharmacodynamics}

Many of buprenorphine's pharmacokinetic properties explain its unique effects (17). Buprenorphine's metabolism follows non-saturable Michaelis-Menten kinetics (18) and furthers its analgesic effects (9). There are two major metabolic pathways in buprenorphine's metabolism. Buprenorphine undergoes $N$-dealkylation catalyzed by the hepatic cytochrome P (CYP) 450 (CYP P450-3A4) and glucuronidation, resulting in three major metabolites: buprenorphine-3-glucuronide (B3G), N-

dealkylbuprenorphine, and norbuprenorphine-3-glucuronide (N3G). The CYP3A4 system metabolizes buprenorphine to norbuprenorphine through $\mathrm{N}$-dealkylation of the cyclopropylmethyl group $(9,18,19)$. Some believe that norbuprenorphine does not readily cross the blood brain barrier (9, although see 21). Sheep are used for the similarity of their blood brain barrier to humans. The peak concentration of buprenorphine was half that in the sagittal sinus relative to arterial quantities which indicated only intermediate permeability across the blood brain barrier. In contrast, the peak concentration and time to peak concentration were very similar for samples from the sagittal sinus and arterial blood for norbuprenorphine. Also noteworthy was that the peak sagittal concentration of norbuprenorphine was over twenty-fold higher than that of buprenorphine in this species (22). Among patients receiving buprenorphine/naloxone for two-weeks, the twenty-four hour area under the concentration curve was equivalent for buprenorphine and norbuprenorphine (23).

Norbuprenorphine is commonly measured in urine analyses because of these high concentrations. Norbuprenorphine and buprenorphine are both detectable in meconium although norburprenorphine's quantities were six-fold higher (24). Another biological matrix that can provide an index of buprenorphine use is hair. The hair of pregnant women and that of their offspring had measurable norbuprenorphine and buprenorphine (25). Norbuprenorphine is then metabolized to N3G $(17,25)$. Other metabolites including hydroxy buprenorphine and hydroxynorbuprenorphine have been identified. CYP3A4 produces hydroxybuprenorphine (18). The CYP3A4 activity varies between individuals and can be induced, resulting in wide differences in pharmacokinetics (18). Buprenorphine is eliminated in the urine and in feces, accounting for one-third and two-thirds of the eliminated buprenorphine, respectively (18).

Glucuronide metabolites of buprenorphine are biologically active, contributing to the pharmacology of this drug (9). The glucuronidation rate is roughly the same for buprenorphine and norbuprenorphine in the liver and small intestine. $N$-dealkylation is one-hundred fold greater in the liver than small intestine. Conjugated metabolites are excreted in bile and half the buprenorphine administered is eliminated in feces (25). In bile fistula rats, where the bile flows into a hollow structure when $0.6 \mathrm{mg} / \mathrm{kg}$ buprenorphine was administered intravenously, $75 \%$ of B3G and $19 \%$ of N3G were excreted in bile. In "linked rat models" or intact rats, approximately twice the amount of N3G was found to be excreted compared to B3G. There are differences in excretion due to first-pass effects in enterohepatic circulation (27). It is deconjugated by the colon by bacteria, then reabsorbed (18).

Buprenorphine is an unusual opioid as a result of its receptor activity at the MOR (9). Buprenorphine has shown activity at all four opioid receptors (3). Buprenorphine dissociates from the MOR slowly, resulting in a slow onset and long duration of analgesic effects (3). A 2002 review describes how the MOR partial agonist and KOR antagonist properties of buprenorphine had been well established but that there had been comparatively less research on DOR and NOR (11). While most opioids show activity at the MOR, DOR, and KOR, buprenorphine is a DOR and KOR antagonist with high affinity (28). Buprenorphine is potent at MOR and DOR, with efficacy at MOR, DOR, and the KOR, in order of descending efficacy (44). The MOR is primarily responsible for analgesic effects as well as euphoria, miosis, constipation, and respiratory depression (17). It may have a greater impact at spinal MOR relative to the brain receptors, which is part of what makes buprenorphine classically considered a partial MOR agonist (9). The DOR has minimal antinociceptive effects relative to the MOR, but have more activity in chronic pain than acute pain. The DOR also participates in analgesic tolerance and physical dependence (17). The KOR has been seen to have analgesic and proalgesic effects to opioids, while also contributing to miosis and sedation (17). The affinity of buprenorphine for NOR (77 $n M$ ) was moderate (Khoryan et al. 2009). Unlike the common presentation of the mechanism of action (Figure 2), buprenorphine is potent at MOR and DOR, with efficacy at MOR, DOR, and the KOR, in order of descending efficacy (44). Figure 2 more accurately reflects the non-selective 
mechanism of action of buprenorphine with high affinity for MOR, KOR, and DOR but low to moderate affinity for NOR.
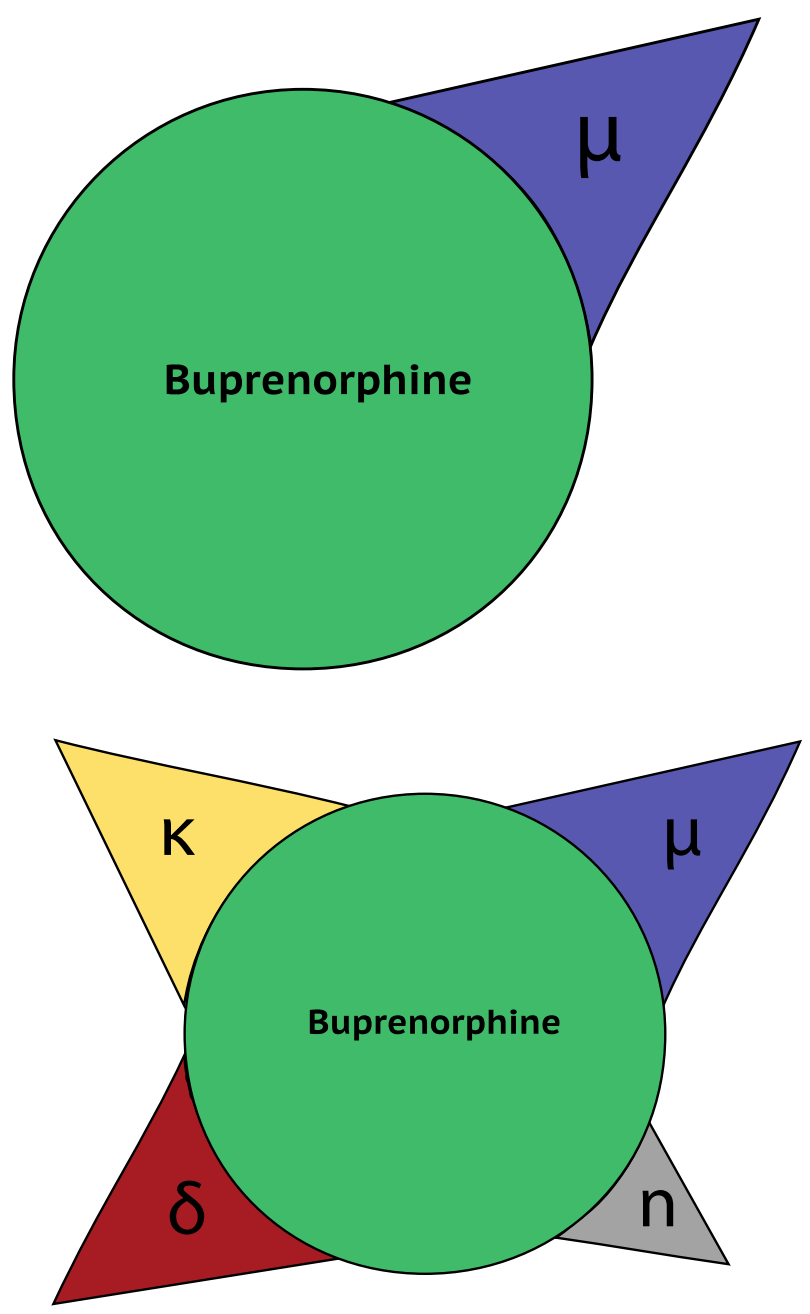

Figure 2. Common depiction of buprenorphine binding selectively to the mu ( $\mu$ ) opioid receptor (top). More complete depiction of buprenorphine's non-selective binding to the four opioid receptors mu, kappa (к), delta $(\delta)$, and nociceptin ( $\mathrm{n}$, bottom, 11, 51).

Buprenorphine's properties including low molecular weight, high lipophilicity, and high potency influence its neurobiological effects. Potency differs dependent on the formulation (29) but a value of ten-fold greater than morphine is generally accepted for pharmacoepidemiological research (30). The drug has a wide tissue distribution and has a peak plasma concentration at ninety minutes (17). Buprenorphine is $96 \%$ protein bound after absorption (9). Oral absorption is considered to be poor because of first-pass metabolism (9). Transdermal absorption is limited but there are formulations designed to be more effective. Sublingual administration is considered effective as well. Some studies consider buccal formulations to be the most efficient with the highest non-intravenous bioavailability (9).

In healthy patients taking buprenorphine/ naloxone tablets, they had peak plasma concentration $\left(\mathrm{T}_{\max }\right)$ of 0.75 $1.0 \mathrm{~h}$ for buprenorphine and $0.5 \mathrm{~h}$ for naloxone, demonstrating rapid absorption. Norbuprenorphine plasma concentrations peaked at a $\mathrm{T}_{\max }$ of $1-1.75 \mathrm{~h}$ after the buprenorphine/naloxone tablet administration. Plasma terminal half-life $\left(\mathrm{t}_{1 / 2}\right)$ was 22 - $39 \mathrm{~h}$ for buprenorphine, 32$44 \mathrm{~h}$ for norbuprenorphine, and a 1.4- 10 for naloxone. Patients who were in withdrawal treatment for opioid dependence had a median $\mathrm{T}_{\max }$ of $0.75-1 \mathrm{~h}$ for buprenorphine, a median $\mathrm{T}_{\max }$ of $0.75-1 \mathrm{~h}$ for norbuprenorphine, and a median $\mathrm{T}_{\max }$ of $0.5-0.75$ (31). In patients with a history of drug addiction, but were drug free at the time of the study, buprenorphine with sublingual and buccal routes had a $51.4 \%$ and $27.8 \%$ bioavailability, respectively (32).

The half-life is dependent on the method of administration with 2 hours for intravenous, 26 hours for the transdermal patch, 28 hours for buccal film, and 37 hours for the sublingual tablet (33). Terminal elimination half-lives were longer in sublingual and buccal routes of administration than the intravenous route which may be due to a depot effect from buprenorphine collected in the oral mucosa tissue reservoirs. The time until the maximum concentration occurs between $0.5-3 \mathrm{~h}$ sublingually and after 20 minutes intravenously (18). Norbuprenorphine had mean peak plasma concentrations that vary by individuals and route of administration in healthy patients $(32,18)$. Intravenous administration of buprenorphine has a $100 \%$, buccal a $46-$ $65 \%$, sublingual a $28-51 \%$, and transdermal a $15 \%$ bioavailability (9). Buprenorphine as a tablet has a bioavailability that is $50-60 \%$ that of a buprenorphine solution $(34 ; 35)$. Buprenorphine's intranasal bioavailability was $70 \%$ with a polyethylene glycol 300 vehicle and $89 \%$ with a dextrose vehicle in sheep (36). Half-life in rats following intravenous administration (2.8 hours, Ohtani et al. 1993) was very similar to humans.

Buprenorphine readily crosses the placenta. However, buprenorphine levels in the third trimester fetal rat brain were only third that of the maternal brain (37). While there is this notion that norbuprenorphine does not readily cross the blood brain barrier (9), this may be age or species dependent. Administration of norbuprenorphine $(3 \mathrm{mg} / \mathrm{kg}$ ) to pregnant rats resulted in higher blood and brain levels in the fetus than in the dam (21). Inhibiting the P-glycoprotein, a drug transporter highly expressed in brain micovessel endothelial cells and placental syncytiotrophoblasts (38) increased rat brain uptake of norbuprenorphine seven-fold (39). The fetal plasma norbuprenorphine area under the curve was approximately two-thirds that of maternal mice. The fetal AUC of norbuprenorphine glucuronide was threefold higher than that of the dam. Although interpretation of this study is somewhat limited by analysis of the entire mouse gestational day fifteen fetus (instead of isolating plasma or brain), these findings indicate appreciable fetal exposure to buprenorphine's biologically active metabolites 
(40). Although buprenorphine and norbuprenorphine are transferred into human breast milk, quantities were low (1\%, 41).

In recent years, it is clearer that different ligands for the same receptor can cause different responses, contrary to traditional receptor theory (42). For receptor theory models to be useful, it must aid in determining the extent in which drug effects can be interpreted and applied to predict future effects (43). The term "ligand bias" has been used to describe opioid analgesic drugs which elicit a different intracellular response, therefore their effects are not only the result of receptor binding affinity (44). Buprenorphine differentiates itself from other opioids with mu-receptor activity with its slow dissociation from the receptor (45). Buprenorphine alone is not responsible for its antagonistic effects, but it's varying metabolite concentration through different forms of drug administration may alter the efficacy of the drug.

Traditionally, buprenorphine is described as a partial MOR agonist known for limited analgesic effects and developed with the intent for limited potential for respiratory depression and addiction (15). However, since buprenorphine's classification in the 1980s and 1990s, what is known about receptor interaction and activation has changed the meaning of the terms "agonist" and "antagonist" $(17,43,46)$. Importantly, categories like full-agonist, partial agonist, and antagonist may be unsatisfactory as a drug's response may land on a continuum (15). Reservations regarding buprenorphine's clinical use were due to misconceptions about an analgesic "ceiling effect" (9). Until recently, agonists like buprenorphine have been known for limited intrinsic activity and inability to produce as large a response at a receptor (16). Initially, it was believed that all agonists for a receptor will result in different degrees of the same intracellular response $(43,46)$. The transduction pathways of a drug activated by an agonist do not act identically for each receptor (4). Partial agonists are known for their lack of intrinsic efficacy (42). The antinociceptive effect ascribed to buprenorphine is considered mainly mediated by MOR (47). Bell-shaped dose-response curves of buprenorphine in the 1980s and 1990s showed there is an optimal range in concentrations for a maximum analgesic effect, with a decrease in activity below or above this range (45). The perception of buprenorphine's clinical usages may depend on the correct application or interpretation of terms from concepts in receptor theory, such as efficacy and agonist (48).

Studies have suggested that different opioid agonists have different downstream effects in the cell, while still binding and activating the same receptor. Therefore, different opioids cannot be considered equivalent by changing the dose (17). It can no longer be assumed that any ligand activating a receptor will produce relatively the same response, with differences attributed to the agonists' efficacies (4). Ligands for a receptor can alter the downstream activity in a pathway, known as biased agonism, ligand-directed signaling, and functional selectivity (49). Opioids that are pure agonists such as morphine or fentanyl produce stronger analgesic effects than drugs like codeine that have decreased receptor binding (50). However, factors such as affinity and efficacy, as well as variables like metabolite binding and concurrent receptor binding may alter the perceived effects and receptor activity of buprenorphine.

The binding affinity of buprenorphine and its metabolites to opioid receptors provide the varied effects seen. Binding affinity is the ability a drug to bind to a receptor, measured by the equilibrium inhibitory constant (Ki) (9). Buprenorphine has a high binding affinity at the MOR and KOR, with debated effects (9). Buprenorphine-3glucuronide had high affinity for MOR $(\mathrm{Ki}=4.9 \mu \mathrm{M})$, and NOR $(\mathrm{Ki}=36 \mu \mathrm{M})$. Norbuprenorphine-3-glucoronide had an affinity for NOR $(\mathrm{Ki}=18 \mu \mathrm{M})$, but not MOR (61). While norbuprenorphine has a greater efficacy, it is considered a less potent partial agonist than buprenorphine at MOR (51). A 2002 review described how norbuprenorphine was much less studied compared to the parent compound but there was some evidence to suggest that it functioned as a MOR and KOR partial agonist and a DOR and NOR full-agonist (11). Figure 3 depicts the affinity of norbuprenorphine for different opioid receptors. Competition assays revealed approximately twenty-five fold lower norbuprenorpine binding to NOR than was found with buprenorphine (51). All metabolites except nubuprenophine-3-glucuronide have analgesic properties $(53,61)$.

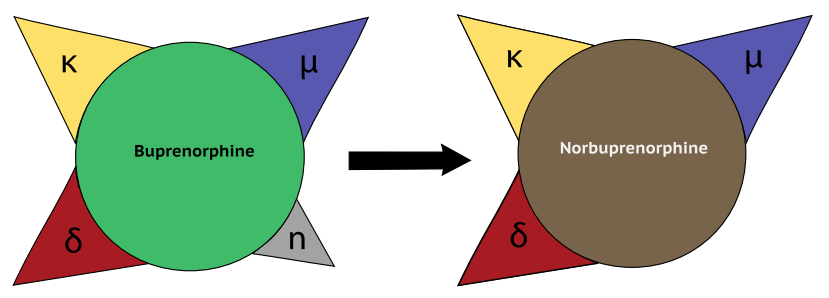

Figure 3. Buprenorphine is metabolized to produce its active major metabolite, norbuprenorphine, which is also a non-selective opioid receptor modulator (mu: $\mu$, kappa: $\kappa$, delta: $\delta$, and nociceptin: $n, 11,51)$.

Buprenorphine alone is not responsible for its analgesic effects, but its varying metabolite concentration through different forms of drug administration may alter the efficacy of the drug. Norbuprenorphine is one of buprenorphine's better researched active metabolites and further research must be done to understand other the metabolites' pharmacodynamics (11). Norbuprenorphine and buprenorphine have substantially different pharmacological profiles. It arises as a result of $\mathrm{N}$-dealkylation catalyzed by cytochrome P450 in the liver $(18 ; 20)$. At the MOR, both norbuprenorphine and buprenorphine are potent partial agonists, with norbuprenorphine having moderate efficacy and buprenorphine having low efficacy. At the NOR, norbuprenorphine has moderate efficacy and buprenorphine having low efficacy, with both substances having low affinity for the receptor. This information was determined using ligand binding experiments and cAMP assay (51). 
Respiratory depression is induced by norbuprenorphine and mediated by MOR (54). There is a low risk of respiratory depression with buprenorphine as a monotherapy and it is rarely considered clinically relevant $(55,56)$.

Buprenorphine's active metabolite, norbuprenorphine, was ten-times more potent for causing respiratory depression (54). Buprenorphine was found to be protective against norbuprenorphine's effect of respiratory depression, both preventing and reversing these effects. An active metabolite of buprenorphine, norbuprenorphine, was alone seen to be responsible for effects of respiratory depression. Binding experiments show DOR and, primarily, MOR as responsible for buprenorphine protecting against the norbuprenorphineinduced respiratory depression (17). The intraventricular administration of buprenorphine and norbuprenorphine showed norbuprenorphine's analgesic activity was $25 \%$ that of buprenorphine (56). Norbuprenorphine was 50-fold less potent than buprenorphine through intravenous administration and 4-fold less potent after intraventricular administration in in vivo animal studies. This decrease in potency may be due to poor penetration across the blood brain barrier compared to buprenorphine (58, although see 22).

When combining results of animal and biochemical studies, norbuprenorphine and buprenorphine are considered by some to be, partial agonists at the mu receptor (58). The co-activation of the NOR by buprenorphine modulates the antinociceptive effect of buprenorphine at opioid receptors (10). Additionally, the mu-opioid receptor may be responsible for counteracting the hyperalgesic effect from NOR. If mu receptors are blocked, NOR produces hyperalgesia (60). Norbuprenorphine, an active metabolite in buprenorphine, had a high binding affinity for the mu receptor and low affinity for the NOR and presented as a potent analgesic with an efficacy equal to buprenorphine in the writhing test (51). Buprenorphine's agonistic effect at the NOR is believed to counter antinociception by buprenorphine and norbuprenorphine on opioid receptors, producing the bell-shaped curves in nociceptive assays (51). Preclinical reports show NOR agonism contributes to decreased analgesia at high concentrations. However, buprenorphine's affinity for the NOR is approximately 50 times lower than its affinity for the MOR and NOR activation causing a pronociceptive effect has not been validated in clinical settings $(1,61,62)$. NOR antagonists had limited impact on buprenorphine induced physiological responses in nonhuman primates (63).

Buprenorphine has a bell-shaped response curve for antinociception and catalepsy (26). The argument can be made that in the clinical setting, the bell-shaped dose response curve has not been demonstrated for pain (26). It may be seen at doses that are much higher than typical clinical doses (18). Buprenorphine was found to be a potent analgesic with full efficacy in mouse models of acute, somatic, and visceral pain. It appears that the analgesic efficacy of buprenorphine is not limited by its categorization as a partial agonist or previous reports of the bell-shaped dose response curve, with a maximal efficacy of the compound was maintained at almost $100 \%$ of the maximal possible effect (64). In clinical studies, no ceiling has been found with buprenorphine's analgesic effect $(55,56)$.

Ascending intravenous doses did not produce any ceiling effect up go $0.6 \mathrm{mg}$ of buprenorphine, roughly equivalent to $10-20 \mathrm{mg}$ of intravenous morphine among healthy humans with acute pain (65). In earlier papers classifying buprenorphine, mention of the ceiling effect seen with the MOR used dose ranges that were relatively equivalent to the potency of other drugs it was tested against such as morphine. A plateau in the dose-effect curve of buprenorphine was identified. However this team noted that dose comparisons between partial and full mu agonist would be made cautiously since extrapolation does not accurately estimate potency (66).

Because of the options for different methods of drug administration (9), buprenorphine's analgesic ability does not appear to be limited and shows promise for pain treatment $(1,5367)$. Preclinical studies have shown the effectiveness of buprenorphine in various pain conditions (68). In conscious rats, buprenorphine was even considered 100 times more potent than morphine (equipotent 0.03- 3.0 $\mathrm{mg} / \mathrm{kg} \mathrm{s.c}$ ) in paw pressure tests, but buprenorphine produced a bell-shaped dose response curve on the hot plate test. The antinociceptive effects of buprenorphine and morphine were equipotent in both paw pressure and hot plate tests when administered intrathecally at 10 micrograms (Bryant et al, 1983). The paw-pressure test with subcutaneous administration showed buprenorphine was more potent than morphine (69). The analgesic potency of buprenorphine $(69,92)$ and its lipophilicity and low molecular weight make buprenorphine ideal for transdermal delivery (70). For this reason, transdermal administration can result in buprenorphine having an increased analgesic efficacy, being 25-50 times more potent than morphine (92). Lower doses of transdermal buprenorphine were required to produce the same equipotency as transdermal fentanyl (69, 2004). In two case studies, buprenorphine gave a positive response where transdermal fentanyl had failed (69). Transdermal administration of buprenorphine in chronic non-cancer, neuropathic, and cancer related pain did not antagonize analgesia and showed beneficial efficacy, safety, or cause withdrawal. Transdermal buprenorphine has been shown to be advantageous for chronic pain treatment (71, 72). Transdermal administration of buprenorphine was efficacious and well tolerated in moderate to severe chronic low back pain (73) and long-term control of chronic pain in cancer patients $(68,74)$. Transdermal buprenorphine was effective for longer term chronic cancer and noncancer pain, with at least satisfactory analgesic effects reported in $90 \%$ of patients (71). Patients with moderate to very severe chronic pain, both cancer and noncancer related, slept longer uninterrupted by pain and of the 239 patients participating, $90 \%$ found satisfactory pain relief and $95 \%$ tolerated the patch well (75).

Buprenorphine's method of administration has implications for the efficacy and clinical benefits or detriments associated with it (53). Buprenorphine is 
considered a potent analgesic when administered intravenously, intramuscularly, buccally, and sublingually for moderate to severe pain (67). Buprenorphine's slow onset time decreases its effectiveness for acute pain (67). However, based on the formulation and method of application, buprenorphine can be approximately 25-100 times more potent than morphine $(3,69,82)$. Intrathecal injections of buprenorphine and morphine showed similar antinociceptive potencies after their peak, but with a shallower dose-response curve for buprenorphine. Similar results were shown through subcutaneous administration in the hot plate test (Bryant et al, 1983). For thermal pain, intrathecal buprenorphine was found to be 17 times more effective than hydromorphone (47). Buccal administration of buprenorphine was effective and tolerable in opioid naïve patients with moderate to severe low back pain $(76,77)$ and general "round-the-clock" chronic pain (78). In a review of thirty-three clinical studies, each trial showed efficacy in buprenorphine for pain relief in the transdermal and buccal forms. Some consider buprenorphine to have the efficacy of a Schedule II drug (79). Buccal film had and similar efficacy and tolerance than the transdermal formulation.

Buprenorphine buccal film (150-900 $\mu \mathrm{g} / 12 \mathrm{~h})$ had similar efficacy than hydromorphone hydrochloride (12-64 mg) (79). Sublingual buprenorphine in the tablet form was 15 time more potent than intramuscular morphine. Sublingual buprenorphine is also active longer than morphine (80). It is shown to be an effective postoperative analgesic $(81,83,84)$. The relative potencies of intramuscular to sublingual buprenorphine was 2:1 among postoperative cancer patients (80). Intramuscular buprenorphine was thirty times more potent than morphine for postoperative pain $(85,86,87)$ and have a longer duration of action than morphine in cancer patients (88).

The classification as a partial antagonist comes in part from the reduced efficacy in morphine and other MOR agonists analgesics when first exposed to buprenorphine. The "antagonist profile" was a conclusion drawn from reduced efficacy if buprenorphine was injected before morphine. Buprenorphine is still a more potent analgesic than morphine and pentazocine in rat tail pressure tests, and marginally more potent than morphine in mouse and rat tail flick tests (89). Buprenorphine's pharmacology allows for it to be combined with other mu-opioid receptor agonists for an additive analgesic effect $(68,90)$. Administering intrathecal morphine and IV buprenorphine simultaneously alleviates pain with decreased sedation and other side effects than either drug alone (91). Additionally, switching between buprenorphine and full mu-agonists is possible without the loss of analgesic efficacy and without refractory period when switching from buprenorphine to new mu-opioid treatment $(67,70)$. Overall, practice guidelines state the importance of patients self-reporting effective analgesics as pain is considered a personal experience that varies based on individual threshold and tolerance (92).

Opioids rarely bind to a single receptor and will have difference in affinities to others. Buprenorphine co-activates other receptors that may play a role in its efficacy. In a partial agonist, the less than full effect should remain the same even with full receptor saturation (93). PET technology shows that buprenorphine can produce analgesia at less than full receptor occupancy, which would make it be considered a full agonist (48). Buprenorphine has a high affinity for MOR, but occupies fewer receptors for analgesia.

Buprenorphine increases MOR expression so that other mu agonists can interact with the receptors (68). Additionally, buprenorphine's activation at the MOR occurs at lower levels of receptor phosphorylation (9). When administering buprenorphine, receptors are available for full agonism at MOR for the treatment of acute pain (9). Some of buprenorphine's negative effects such as respiratory depression and abuse can be attributed to peripheral DOR (94). While opioid analgesics like buprenorphine often bind to the MOR, there is a variation in their affinity for this receptor as well as their affinity ratio for other receptors, such as the previously mentioned NOR, in addition to KOR and DOR (17). Buprenorphine has antagonistic activity at the KOR that causes antihyperalgesic effects to some extent (70). The antihyperalgesic effects of buprenorphine have successfully treated neuropathic pain ( 71,82 95), which may show neuropathic pain may be more susceptible to buprenorphine than other opioids (70). Antagonism from the KOR activation leads to predictions that drugs with lower affinity for the KOR relative to MOR will be effective in producing MOR-related effects 17). However,

buprenorphine's KOR activity is debated to be a partial agonist $(51,96)$, antagonist (97), and even thought to have no activity $(92,98)$. Some believe buprenorphine is an KOR antagonist or inverse agonist (9). Therefore, considering these mixed results (17), KOR may have limited contribution to buprenorphine's activity. Additionally, dimers of the receptors can arise as homo- or hetero-conformations, that may have distinct signals (99). MOR-DOR and DOR-KOR specific agonists have different signal, outcomes, and antinociceptive results $(17,90,100)$.

Despite full MOR occupancy, partial agonism is present in buprenorphine with a partial respiratory effect. (55). Respiratory depression in buprenorphine varies depending upon method of drug administration. This was significant in animals, even when norbuprenorphine was in greater concentrations than buprenorphine in the plasma (17). The dose-effect relationship of buprenorphine with respiratory depression suggests limited effects or a plateau of effects over a $0.008-3 \mathrm{mg} / \mathrm{kg}$ intravenous dose range (55). Although the dose-response curve shows a plateau, the idea that respiratory effects are limited is dangerous since buprenorphine in combination with drugs like sedatives can cause fatal respiratory depression (55). Respiratory effects are rarely reported in maintenance therapy but, in situations of misuse, features of opioid poisoning can be present with buprenorphine (17).

\section{Misuse potential}

A growing number of patients are being treated for opioid use disorder in the United States using methadone, injectable naltrexone, and buprenorphine. Buprenorphine is 
the most widely prescribed for opioid use disorder in substance use treatment facilities (101). Buprenorphine is generally believed to have a low misuse potential alone, particularly when formulated with naloxone.

Two common preclinical methods to assess misuse potential in non-human species are self-administration and conditioned place preference. Buprenorphine could initiate and maintain self-administration in rhesus monkeys with a morphine history and among one who was opioid naïve (102). Three of four tested baboons intravenously selfadministered buprenorphine $(1 \mathrm{mg} / \mathrm{kg})$ but at rates half that of codeine (103). The threshold of brain stimulation reward to the median forebrain bundle was reduced by buprenorphine in rats (104). Buprenorphine could maintain self-administration in rats but, unlike with other opioids (fentanyl, oxycodone), use did not escalate over time (105).

Conditioned place preference (CPP) involves classical conditioning and whether a rodent finds a drug and its associated environment positive, neutral, or negative (i.e. conditioned place aversion). Rats form a CPP to subcutaneous (0.025-0.010 mg/kg) buprenorphine (106). Wild type mice also showed a CPP to a higher $(3 \mathrm{mg} / \mathrm{kg})$ dose but MOR knock-outs did not (107). The combination of diazepam with a buprenorphine dose $(1 \mathrm{mg} / \mathrm{kg})$ that was ineffective by itself produced a CPP (108). There also was a synergistic CPP effect between buprenorphine and cocaine (109).

Two other procedures that provide mechanistic insights into misuse potential for a drug by targeting the nucleus accumbens, a brain structure important for reward, are microdialysis and fast-scan voltammetry. Microdialyis revealed a doubling, albeit over five-hours, in dopamine from the nucleus accumbens following buprenorphine. The combination of buprenorphine and cocaine produced a larger increase in dopamine than only cocaine (109). Voltammetry showed that buprenorphine could produce an intermediate (25\%) nucleus accumbens shell response to buprenorphine which was less than that observed with heroin $(60 \%$, Isaacs et al. 2020).

There are many studies noting an increasing trend in the misuse, diversion, and self-medication of buprenorphine for withdrawal symptoms. (101). When France introduced buprenorphine in the 1990s (i.e. before the US), they quickly had cases of asphyxic deaths from misuse or concomitant drug ingestion of psychotropic drugs like benzodiazepines and neuroleptics $(17,111)$. The Drug Abuse Warning Network stated that emergency department visits associated with buprenorphine have grown, with a significant amount resulting from nonmedical use (112). Benzodiazepine prescription was associated with increased risk of opioid overdose, mortality, and, in those using buprenorphine, decreased discontinuation of buprenorphine (101). Although labelled for sublingual use, buprenorphine was injected by $33 \%$ of users (17). Fatality is typically associated with intravenous misuse, through injection of crushed tablets (17). Among Massachusetts residents, thirty-one per cent of the 183 overdoses occurred when individuals used benzodiazepines and buprenorphine (101). Driving under the influence cases where buprenorphine is implicated almost always also involved other drugs (113).

The general consensus of buprenorphine having low, relative to that of full-agonists, misuse potential, should not be confused with an absence of misuse potential 12,13). The crowd-sourced harm-reduction site Erowid contains reports of buprenorphine and buprenorphine-naloxone recreational experiences $(114,115)$. Sites like these provide instructions to dissolve formulations of buprenorphine/naloxone for intravenous use (116). According to the 2,481 submissions to the crowdsourcing site streetrx.com, the street value of buprenorphine/naloxone was only $20 \%$ less than that of buprenorphine mono-products. The black-market value of US\$ $3.95 / \mathrm{mg}$ indicates that there is some non-medical use (117). A prior report using this database found that buprenorphine's street value was lower (US\$2.13 mg) but still over twice that of another high-potency opioid, methadone (US\$0.96, 118). Similarly, Maine’s Diversion Alert Program reported on arrests involving illicit or prescription drugs. Arrests for buprenorphine $(\mathrm{N}=147)$ exceeded those for oxycodone, hydrocodone, methadone, tramadol and morphine, combined (119).

\section{Toxicology}

Buprenorphine has adverse effects similar to other opioids. Buprenorphine produces dizziness, nausea, vomiting, sedation, respiratory depression, and constipation. It produces more sweating than codeine, dextropropoxyphene, oxycodone, and pentazocine (18). The acute toxicity $\left(\mathrm{LD}_{50}\right)$ of buprenorphine varies based on the method of drug administration (See table 1, from 92). When comparing norbuprenorphine and buprenorphine through intravenous administration, the $\mathrm{LD}_{50}$ is 146.5 and $234.6 \mathrm{mg}$ $\mathrm{kg}^{-1}$, respectively, and was found to have a norbuprenorphine-to-buprenorphine $\mathrm{LD}_{50}$ ratio of $1 / 16-1 / 23$ (17) Buprenorphine is protective against the depressive effects of norbuprenorphine on ventilation.

The dose-effect relationship of buprenorphine with respiratory depression suggests limited effects or a plateau of effects over a $0.008-3 \mathrm{mg} / \mathrm{kg}$ intravenous dose range (55). In a study with healthy volunteers, intramuscular buprenorphine (0.15- $1.2 \mathrm{mg}$ ) increased the risk of respiratory depression linearly, but the effect was not clinically significant (120). With sublingual buprenorphine (1-31 mg), patients reached respiratory depression at doses $8 \mathrm{mg}$ or more (66). A study on 50 postoperative patients with intravenous buprenorphine (0.4- $7.0 \mathrm{mg}$ ) showed no signs of respiratory depression for a $24 \mathrm{~h}$ period (121). Healthy volunteers with intravenous buprenorphine $(0.1 \mathrm{mg} / 70 \mathrm{~kg}$ body weight $)$ demonstrated a ceiling in respiratory depression, but not in analgesic efficacy $(56,59)$. Animal experiments show that the respiratory ceiling occurs at a lower dose $(>0.2 \mathrm{mg} / \mathrm{kg})$ than the analgesic effect ceiling, which will only occur in doses beyond the therapeutic dose range $(56,65)$. Respiratory effects are rarely reported in maintenance therapy, but in situations of abuse, features of opioid poisoning can be 
present with buprenorphine (17). Experimental and clinical data show that there is a limit on buprenorphine's maximum depressant effect (70). Although the dose-response curve shows a plateau, the idea that respiratory effects are limited is dangerous since buprenorphine in combination with drugs like sedatives can cause fatal respiratory depression (55).

Drug interactions may modify the adverse effects of buprenorphine. Many drugs interact with cytochrome P450 (CYP) 3A4. HIV Protease inhibitors can disrupt buprenorphine $\mathrm{N}$-dealkylation, leading to increased levels of buprenorphine exposure. Azole antifungals like ketoconazole and itraconazole inhibit CYP3A4 (122). Macrolides and azole anti-fungals slow metabolism of norbuprenorphine (18). Some selective serotonin reuptake inhibitors such as norfluoxetine and fluvoxamine were seen to inhibit buprenorphine $\mathrm{N}$-dealkylation in vitro, but with higher $\mathrm{Ki}$ values of $100 \mathrm{micromol} / \mathrm{L}$ and $260 \mathrm{micromol} / \mathrm{L}$, it is not expected to inhibit metabolism in vivo (122). Antiseizure drugs like carbamazepine phenobarbital and phenytoin accelerate buprenorphine metabolism in the conversion of buprenorphine to norbuprenorphine (18). Tricyclic antidepressants, benzodiazepines, and neuroleptics increase sedation with buprenorphine (18). The mechanism for respiratory effects from buprenorphine is unknown and not responsive to naloxone $(17,123)$. However, contradictory reports have been noted where patients show improvement using 0.4 -0.8 mg of naloxone (17).

Buprenorphine has an increased potential for misuse when central nervous system depressants like benzodiazepines are used simultaneously (101).

Benzodiazepines are not CYP3A4 inhibitors, but some like diazepam and flunitrazepam are metabolized through this enzyme. This drug interaction is likely additive or synergistic (122). Interactions between benzodiazepines and opioids as well as buprenorphine and methadone has resulted in respiratory depression in animal models and humans (17, 122). Opioids and benzodiazepines act in combination with different classes of opioid and GABA receptors, but only limited interactions have been reported (17). Benzodiazepine and buprenorphine's concurrent use causes a decreased reaction time and is associated with increased risk for emergency room visits for accidental injury (101). It should be noted that many addicts use benzodiazepines during treatment (17). However, while one third of patients are prescribed both buprenorphine and benzodiazepines, approximately another third regularly use illegally obtained benzodiazepines, making it difficult to decrease the risk of substance use relapse. Because of the concern benzodiazepines might impede opioid maintenance therapy, the US Food and Drug Administration urged withholding opioid agonist treatment if the patient is taking benzodiazepines 101). Pharmacodynamic interaction is the expected cause of buprenorphine benzodiazepine drug interaction found in humans and animals. However, flunitrazepam-buprenorphine drug interaction is thought to have a pharmacokinetic interaction Flunitrazepam alters buprenorphine lethality in rat with a 6-fold decrease of its $\mathrm{LD}_{50}$, which appears to be opioid-specific as there was only a 2-fold decrease in methadone and no significant effect on morphine (17)

Some studies show here is a significant amount of norbuprenorphine remaining in plasma following buprenorphine's administration (124), contrary to others (56). Reported buprenorphine overdoses in the mid 2000s can be related to varied norbuprenorphine plasma concentrations (125), which can be related to method of administration $(17,32)$. Buprenorphine's clearance in anesthetized patients was seen to be lower than individuals not under anesthesia, as well as in patients with reduced hepatic blood flow as a result of another administered anesthetic (84). Fatal cases related to buprenorphine have had high plasma or tissue concentration of norbuprenorphine, suggesting its role as a respiratory depressor may be a significant future consideration in buprenorphine's toxicity. Significant respiratory depression has been found in rats with a single intravenous administration of $3 \mathrm{mg} / \mathrm{kg}$ norbuprenorphine. The mechanism for respiratory effects from buprenorphine is unknown and not responsive to naloxone. $(17,122)$. However, contradictory reports have been noted where patients show improvement using $0.4-0.8 \mathrm{mg}$ of naloxone (17). It is still unclear if norbuprenorphine alone is significant enough to be a cause of a buprenorphine-related death (17). Respiratory depression in buprenorphine varies depending upon method of drug administration as well. Despite full MOR occupancy, partial agonism is present in buprenorphine with a partial respiratory effect. (55). This was significant in animals, even when norbuprenorphine was in greater concentrations than buprenorphine in the plasma. (17). The dose-effect relationship of buprenorphine with respiratory depression suggests limited effects or a plateau of effects over a $0.008-3 \mathrm{mg} / \mathrm{kg}$ intravenous dose range (55). Although the dose-response curve shows a plateau, the idea that respiratory effects are limited is dangerous since buprenorphine in combination with drugs like sedatives can cause fatal respiratory depression. (55). Respiratory effects are rarely reported in maintenance therapy, but in situations of abuse, features of opioid poisoning can be present with buprenorphine (17). It would be difficult to understate the importance of polysubstance use among decedents where buprenorphine was identified (126). An investigation of 117 fatalities that tested positive for buprenorphine found that benzodiazepines and neuroleptics were also present (111). A report from Rhode Island of opioid overdose cases that were positive for buprenorphine discovered that the average number of drugs and metabolites on toxicology testing was nine (127).

Poison control reports involving buprenorphine increased by $67 \%$ from 2011 until 2016 (112). Decreased age may increase the sensitivity to buprenorphine induced respiratory depression which can be severe enough to require naloxone treatment. Some overdoses involved an orange, hexagon-shaped, lemon lime flavored sublingual tablet (128) while others reported an intravenous formulation for veterinary use (129). Buprenorphine was placed on the list of drugs that can be fatal with a single dose for a $10 \mathrm{~kg}$ toddler 
(130). There have been case reports of a child fatalities following accidental buprenorphine/naloxone exposure. A ten-month old infant was found unresponsive eight-hours after a family member removed a sublingual buprenorphine/naloxone $(8 \mathrm{mg} / 2 \mathrm{mg}$ ) pill from his mouth. Postmortem toxicology revealed serum concentration of 52 $\mathrm{ng} / \mathrm{ml}$ buprenorphine and $39 \mathrm{ng} / \mathrm{ml}$ norbuprenorphine but he tested negative for other illicit, prescription, or over-thecounter drugs (131). Among the over eleven-thousand reports from 2007 to 2016 involving buprenorphine to US poison control centers involving children and adolescents (age $\leq 19$ ), the vast majority involved children younger than six $(86.1 \%)$ and were unintentional $(89.2 \%, 132)$. A controlled study in infants and toddlers found that buprenorphine $(1.5$ or $3 \mu \mathrm{g} / \mathrm{kg}$ ) produced a greater respiratory depressant effect than morphine (50 or 100 $\mu \mathrm{g} / \mathrm{kg}, 133)$. Findings like this have prompted calls for improved education on safe buprenorphine storage in a locked medicine cabinet or storage box in its original container and disposal (134) and greater use of child resistant packaging (135).

\section{Prenatal correlates and consequences}

Methadone or buprenorphine, in combination with counseling and behavioral therapy, are currently considered first-line for pregnant women with opioid use disorder (136). The cellular targets of buprenorphine and norburpenorphine (KOR, MOR, NOR, Figure 3) may serve different functions during development $(5,6)$ than they do in the adult brain. There is a preclinical literature, primarily in rats, that has identified abnormalities in a wide-variety of structural and functional endpoints following prenatal buprenorphine exposure. Mice have unusual buprenorphine pharmacokinetics including only modest amounts of norbuprenorphine crossing the blood brain barrier $(52,137$, 138) which is unlike sheep (22). Another possibility that could account for the differences among studies is that analytical chemistry procedures have been refined. The selection of dosing regimens for use in rats, with their proportionally larger liver, faster metabolisms but shorter pregnancies (three weeks), that is clinically relevant to humans is not trivial (139). Maintenance doses of 3-24 mg per day are employed in a $70 \mathrm{~kg}$ persons which translates to 0.04 to $0.34 \mathrm{mg}$ per $\mathrm{kg}$ body weight although doses of 0.41 have been reported (41). The rat doses of 0.3 to $3.0 \mathrm{mg} / \mathrm{kg}$, often administered subcutaneously or by implantable minipumps, may therefore be considered clinically relevant. A minor caveat is the mini-pumps release a fixed dose per day but, on a $\mathrm{mg} / \mathrm{kg}$ basis, this may decrease somewhat as maternal body weight increases during pregnancy (140). Oligodendrocytes make myelin and express opioid receptors. Prenatal and early postnatal, to correspond to third-trimester human brain development, buprenorphine ( $1 \mathrm{mg} / \mathrm{kg}$ per day) from day seven of gestation until postnatal day twenty-one decreased myelinated axons at twenty-six days of age in the corpus callosum (141). A subsequent investigation determined that prenatal and early postnatal treatments with 1 , but not $0.3, \mathrm{mg} / \mathrm{kg}$ reduced overall brain mass in males and females at postnatal day 21 (110). This dosing regimen reduced brain derived neurotrophic factor and biochemical parameters of neural stem and progenitor cells (142). A 0.5 $\mathrm{mg} / \mathrm{kg}$ dose to pregnant rats for one-week induced a subtle, but statistically significant (18\%) down-regulation in MOR binding in the brain of dams but a $64 \%$ decline in the offspring indicating that the developing brain was more sensitive (143).

A meta-analysis of the six rat investigations that studied brain function determined that perinatal buprenorphine impacted a variety of domains including rodent models of emotion, cognition, and responsiveness to addictive drugs (144). Prenatal exposure to 1 , but not 0.3 , $\mathrm{mg} / \mathrm{kg}$ buprenorphine increased immobility, independent of sex, on the forced swimming and tail suspension tests (110). This profile of behavior was replicated, albeit by the same laboratory, and is interpreted as an increase in depressionlike behavior $(142,145)$. Young-adult rats that had received buprenorphine perinatally $(1 \mathrm{mg} / \mathrm{kg})$ showed a pronounced deficit in recognition memory (37). The view that $1 \mathrm{mg} / \mathrm{kg}$ was the threshold to produce neurobehavioral effects was challenged by a recent investigation that identified decreased maternal care, delays in offspring maturation, and abnormalities in response to a painful stimuli at the 0.3 $\mathrm{mg} / \mathrm{kg}$ dose (150)

Given that the neurostructural (e.g. decreased myelination (6) and nerve growth factor (146) and behavioral effects were causally linked to perinatal buprenorphine in rats and that this is a rapidly expanding research area, it is important to verify these results in humans. Unfortunately, this is an extremely difficult area to study. The principle challenge is that although buprenorphine is an evidence based intervention to reduce other opioid use (147), it does not eliminate it. For example, of nine women receiving buprenorphine who completed thrice weekly urine testing during pregnancy, all tested positive at least once for other opioids. An average of onequarter of samples were positive but this ranged from 4 to $75 \%$ (24). Untangling the contribution of illicit and prescription opioids to maternal and fetal outcomes is not trivial (139). Other challenges includes determining the involvement of prenatal alcohol, nicotine (148), maternal stress and diet, prenatal care, or the postnatal environment. If that were not enough, this can be an inherently challenging population and treatment retention is lower with buprenorphine than with methadone (147). Despite these many caveats, a meta-analysis of the offspring of mothers receiving opioid maintenance during pregnancy showed lower scores relative to an unexposed comparison group for vision (effect size $=0.25)$, motor activity (0.37), attention and executive functioning (0.40), and psychomotor function (0.56). The magnitude of the overall effect size (0.49) was equivalent to a 7 point IQ deficit (144). The literature in this area is not sufficiently advanced to differentiate whether methadone or buprenorphine is correlated with more adverse outcomes (149). Given the more complex 
pharmacodynamics of buprenorphine and its metabolite (Figure 3 ) and the increasing availability of buprenorphine (8, Figure 1$)$, this should be a high priority area for further study.

\section{CONCLUSION}

Buprenorphine is widely used for opioid use disorder, including during pregnancy, and pain. Distinctions between "weak" and "strong" opioids or "full" and "partial" agonists may be needed to account for "weak" opioids like buprenorphine having characteristics considered "strong" (17). This is ineffective if used clinically, as "weak" opioids are considered less likely to lead to addiction and adverse side effects, while this can be seen as untrue for buprenorphine. Reducing diversion may require developing new misuse-deterrent formulations of buprenorphine (112). More work needs to be done in determining drug interactions with buprenorphine that are the result of some interaction or inhibition with metabolizing enzymes like CYP3A4 and CYP2C8. Synergistic or additive effects by other opioids, alcohol, and neuroleptics should be considered (17). Preclinical investigations are necessary that examine age differences in sensitivity to adverse effects like respiratory depression. The brain structure (141) and functional abnormalities in rats following relatively low perinatal doses $(110,145,150)$ are concerning and may warrant follow-up (e.g. Diffusion Tensor Imaging to evaluate white matter integrity in buprenorphine exposed nonhuman primates or children). Clinical studies are needed to determine the ceiling for analgesia in humans and the dose it occurs at (55). Additionally, without taking into account the full effects of the metabolites' transduction based on method of administration, there can be adverse effects as a result of residual effects of buprenorphine's metabolism. The bioavailability of certain metabolites in plasma, like norbuprenorphine, requires more research as this has implications on medications that can be co-administered with buprenorphine. Without taking into consideration of factors such as method of administration, this can lead to incorrect assumptions in the efficacy of the opioid prescribed. Additionally, without taking into account the full effects of the metabolites' transduction based on method of administration, there can be adverse effects as a result of residual effects of buprenorphine's metabolism. Some information sources (13) describe the mechanism of action of buprenorphine as simply a mu-partial agonist and provide limited information about the major, and biologically active, metabolite norbuprenorphine which may be a considerable oversimplification (top of Figure 2 versus Figure 3 ). Continued efforts to better understand the complex pharmacodynamics and pharmacokinetics of buprenorphine and metabolites will result in a better appreciation of the benefits, and risks, of this ubiquitous opioid.

\section{ACKNOWLEDGEMENTS}

Thanks to Stephanie Nichols, PharmD for feedback on an earlier version of this review. Iris Johnston provided technical assistance.

Ethical review committee: University of New England (Approval number: \#20180410-009).

\section{REFERENCES}

[1] Davis, M.P.; Pasternak, G.; Behm, B. Treating chronic pain: An overview of clinical studies centered on the buprenorphine option. Drugs, 2018; 78(12), 1211-1228. https://pubmed.ncbi.nlm.nih.gov/30051169/ (Accessed March 22, 2020).

[2] Campbell, N.D. and Lovell, A.M. The history of the development of buprenorphine as an addiction therapeutic. Ann. NY Acad. Sci., 2012, 1248, 124-139. https://pubmed.ncbi.nlm.nih.gov/22256949/ (Accessed March 14, 2020).

[3] Jasinski, D.R.; Pevnick, J.S.; Griffith, J.D. Human pharmacology and abuse potential of the analgesic buprenorphine: a potential agent for treating narcotic addiction. Arch Gen Psychiatry, 1978, 35(4), 501-516. https://pubmed.ncbi.nlm.nih.gov/215096/ (Accessed March 9, 2020).

[4] Cox, B.M.; Christie, M.J.; Devi, L.; Toll, L.; Traynor, J.R. Challenges for opioid receptor nomenclature: IUPHAR review 9. Br. J. Pharmacol., 2014, 172, 317323. https://www.ncbi.nlm.nih.gov/pmc/articles/PMC429294 9/ (Accessed Nov 10, 2020).

[5] Tan, K.Z.; Cunningham, A.M.; Joshi, A.; Oei, J.L.; Ward, M.C. Expression of kappa opioid receptors in developing rat brain - Implications for perinatal buprenorphine exposure. Reprod. Toxicol., 2018, 78, 8189 https://pubmed.ncbi.nlm.nih.gov/29635048/.

(Accessed Nov 11, 2020).

[6] Eschenroeder, A.C.; Vestal-Laborde, A.A.; Sanchez, E.S.; Robinson S.E.; Sato-Bigbee, C. Oligodendrocyte responses to buprenorphine uncover novel and opposing roles of $\mu$-opioid- and nociceptin/orphanin FQ receptors in cell development: Implications for drug addiction. Glia, 2012, 60, 125-136. https://onlinelibrary.wiley.com/doi/abs/10.1002/glia.212 53. (Accessed Nov 11, 2020).

[7] Kogan, L.; Hellyer, P.; Rishniw, M.; SchoenfeldTacher, R. The US opioid epidemic and its impact on US general practice veterinarians. Front. Vet. Sci., 2019, 6:222.

https://www.ncbi.nlm.nih.gov/pmc/articles/PMC662078 8/ (Accessed Nov 11, 2020). 
[8] Pashmineh, A.A.; Cruz-Mullane, A.; Podd, J.C.; Lam, W.S.; Kaleem, S.H.; Lockard, L.B.; Mandel, M.R.; Chung, D.Y.; Simoyan, M.O.; Nichols, S.D.; McCall, K.L.; Piper, B.J. Rise and regional disparities in buprenorphine utilization in the United States. Pharmacoepidemiol. Drug Saf., 2019, 29(6), 1-8. https://onlinelibrary.wiley.com/doi/abs/10.1002/pds.498 4 (Accessed Nov 9, 2020).

[9] Gudin, J. and Fudin, J. A narrative pharmacological review of buprenorphine: a unique opioid for the treatment of chronic pain. Pain Ther., 2020, 9(1), 41-54. https://www.ncbi.nlm.nih.gov/pmc/articles/PMC720327 1/ (Accessed Nov 10, 2020).

[10] Lutfy, K. and Cowan, A. Buprenorphine: A unique drug with complex pharmacology. Curr. Neuropharmacol., 2004, 2, 395-402. https://www.ncbi.nlm.nih.gov/pmc/articles/PMC258140 7/ (Accessed Nov 11, 2020).

[11] Robinson, S.E. Buprenorphine: An analgesic with an expanding role in the treatment of opioid addiction. CNS Drug Rev., 2002, 8, 377-390.

https://www.ncbi.nlm.nih.gov/pmc/articles/PMC674169 2/ (Accessed Nov 11, 2020).

[12] American Society of Addiction Medicine. Treatment of opioid use disorder course.

https://www.asam.org/docs/default-source/practicesupport/guidelines-and-consensus-docs/asam-nationalpractice-guideline-supplement.pdf (Accessed Sept, 1, 2020).

[13] Provider Clinical Support System. 8-hour MAT waiver training for physicians. https://pcssnow.org/ (Accessed Sept 1, 2020).

[14] Stahl, S.M. Stahl's essential psychopharmacology: Neuroscientific basis and practical applications., $4^{\text {th }} \mathrm{ed}$.; Cambridge University Press: Cambridge, 2013.

[15] Yaksh, T. and Wallace, M. Goodman \& Gilman's: The Pharmacological Basis of Therapeutics [Online]; 13ed.; McGraw-Hill: New York, 2018.

https://accessmedicine.mhmedical.com/content.aspx?bo okid $=2189 \&$ sectionid $=170269577$ (Accessed Nov 10, 2020).

[16] Emery, M.A. and Eitan, S. Members of the same pharmacological family are not alike: Different opioids, different consequences, hope for the opioid crisis?. Prog Neuropsychopharmacol Biol Psychiatry, 2019, 92, 428449.

https://www.sciencedirect.com/science/article/abs/pii/S0 278584618305475 (Accessed Nov 10, 2020).
[17] Mégarbane, B.; Hreiche, R.; Pirnay, S.; Marie, N.; Baud, F.J. Does high-dose buprenorphine cause respiratory depression?: Possible mechanisms and therapeutic consequences. Toxicol. Rev., 2006, 25(2), 79-85. https://pubmed.ncbi.nlm.nih.gov/16958555/ (Accessed Jan 9, 2020).

[18] Davis, M.p. Buprenorphine in cancer pain. Support Care Cancer, 2005, 13(11), 878-887. https://pubmed.ncbi.nlm.nih.gov/16010532/ (Accessed Nov 10, 2020).

[19] Iribarne, C.; Picart, D.; Dréano, Y.; Bail, J.P.; Berthou, F. Involvement of cytochrome P450 3A4 in Ndealkylation of buprenorphine in human liver microsomes. Life Sci., 1997, 60(22),1953-1964. https://pubmed.ncbi.nlm.nih.gov/9180349/ (Accessed Nov 10, 2020).

[20] Kobayashi, K.; Yamamoto, T.; Chiba, K.; Tani, M.; Shimada N.; Ishizaki T.; Kuroiwas Y. Human buprenorphine N-dealkylation is catalyzed by cytochrome P450 3A4. Drug Metab. Dispos., 1998, 26(8), 818-821.

https://pubmed.ncbi.nlm.nih.gov/9698298/ (Accessed Nov 10, 2020).

[21] Griffin, B.A.; Capterton, C.O.; Russel, L.N.; Cabanlong, C.V.; Wilson, C.D., Urquhart, K.R.; Martins, B.S.; Zita, M.D.; Patton, A.L.; Alund, A.W.; Owens, S.M.; Fantegrossi, W.E.; Moran, J.H,; Brents, L.K. In utero exposure to norbuprenorphine, a major metabolite of buprenorphine, induces fetal opioid dependence and leads to neonatal opioid withdrawal syndromes. J. Pharmacol. Exp. Ther., 2019, 370, 9-17. https://pubmed.ncbi.nlm.nih.gov/31028107/ (Accessed Nov 11, 2020).

[22] Jansen, M.L.; Foster, D.; Upton, R.; Grant, C.; Martinez, A.; Somogyi, A. Comparison of cerebral pharmacokinetics of buprenorphine and norbuprenorphine in an in vivo sheep model. Xenobiotica, 2007, 37, 441-457. https://www.tandfonline.com/doi/abs/10.1080/00498250 701251126 (Accessed Nov 11, 2020).

[23] Gruber, V.A.; Rainey, P.M.; Moody, D.E.; Morse, G.D.; Ma, Q.; Prathikanti, S,; Pade, A.P.; Alvanzo, A.H.; McCane-Katz, E.F. Interactions between buprenorphine and the protease inhibitors darunavirritonavir and rosamprenavir-ritonavir. Clin. Infect. Dis., 2012, 54, 414-423.

https://www.ncbi.nlm.nih.gov/pmc/articles/PMC325827 0/ (Accessed Nov 11, 2020).

[24] Kacinko, S.L.; Jones, H.E.; Johnson, R.E., Choo, R.E.; Huestis, M.A. Correlations of maternal buprenorphine 
dose, buprenorphine, and metabolite concentrations in meconium with neonatal outcomes. Clin. Pharmacol. Ther., 2008, 84, 604-612.

https://pubmed.ncbi.nlm.nih.gov/18701886/ (Accessed Nov 11, 2020).

[25] Goodwin, R.S.; Wilkins, D.G.; Averin, O.; Choo, R.E.; Schroeder, J.R.; Jasinski, D.R.; Johnson R.E., Jones, H.E.; Huestis, M.A. Buprenorphine and norbuprenorphine in hair of pregnant women and their infants after controlled buprenorphine administration. Clin. Chem., 2017, 53, 2136-2143. (Accessed Nov 11, 2020).

[26] Ohtani, M. Basic pharmacology of buprenorphine. Eur J. Pain Suppl., 2007, 1, 69-73. https://onlinelibrary.wiley.com/doi/abs/10.1016/S17543207\%2808\%2960017-6 (Accessed Nov 11, 2020).

[27] Ohtani, M.; Kotaki, H.; Uchino, K.; Sawada, Y,; Iga, T. Pharmacokinetic analysis of enterohepatic circulation of buprenorphine and its active metabolite, norbuprenorphine, in rats. J. Pharmacol. Exp. Ther., 1994, 22, 2-7.

https://pubmed.ncbi.nlm.nih.gov/8149883/ (Accessed Nov 11, 2020).

[28] Khroyan, T.V.; Wu, J.; Polgar, W.E.; CamiKobeci, G.; Fotaki, N.; Husbands, S.M.; Toll, L. BU08073 a buprenorphine analogue with partial agonist activity at mu-receptors in vitro but long-lasting opioid antagonist activity in vivo in mice. Br. J. Pharmacol., 2015, 172(2), 668-680.

https://www.ncbi.nlm.nih.gov/pmc/articles/PMC429297 7/ (Accessed Nov 10, 2020).

[29] Centers for Medicare and Medicaid Services. Opioid oral morphine milligram equivalent (MME) conversion factors. https://www.cms.gov/Medicare/PrescriptionDrug-

Coverage/PrescriptionDrugCovContra/Downloads/Opioi d-Morphine-EQ-Conversion-Factors-April-2017.pdf. (Accessed Oct 26, 2020).

[30] Piper, B.J.; Shah, D.T.; Simoyan, O.M.; McCall, K.L.; Nichols, S.D. Trends in medical use of opioids in the U.S., 2006-2016. Am. J. Prev. Med., 2018, 54(5), 652660. https://pubmed.ncbi.nlm.nih.gov/29551331/ (Accessed Nov 11, 2020).

[31] Dong, R.; Wang, H.; Li, D.; Lang, L.; Gray, F.; Liu, Y.; Laffont, C.M.; Young, M.; Jiang, J.; Liu, Z.; Learned, S.M. Pharmacokinetics of sublingual buprenorphine tablets following single and multiple doses in Chinese participants with and without opioid use disorder, Drugs R. D., 2019, 19(3), 255- 265. https://www.ncbi.nlm.nih.gov/pmc/articles/PMC673835 9/ Accessed Nov 11, 2020).
[32] Kuhlman, J.J. Jr.; Lalani, S.; Magluilo, J. Jr.; Levine, B.; Darwin, W.D.; Johnson, R.E., Cone, E.J. Human pharmacokinetics of intravenous, sublingual, and buccal buprenorphine. J. Anal. Toxicol., 1996, 20(6), 369-378. https://academic.oup.com/jat/article/20/6/369/777488 (Accessed Nov 11, 2020).

[33] Lexicomp. Buprenorphine drug information. Hudson, Ohio, 2013 UpToDate, Inc.; (Accessed Oct 27, 2020).

[34] Nath, R.P.; Upton, R.A.; Everhart, E.T.; Cheung, P.; Shwonek, P.; Jones, R.T.; Mendelson, J.E. Buprenorphine pharmacokinetics: relative bioavailability of sublingual tablet and liquid formulations. J. Clin. Pharmacol., 1999, 39, 619-623. https://accp1.onlinelibrary.wiley.com/doi/abs/10.1177/0 0912709922008236 (Accessed Nov 11, 2020).

[35] Schuh, K.J. and Johanson, C.E. Pharmacokinetic comparison of the buprenorphine sublingual liquid and tablet. Drug Alcohol Depend.,1999, 56(1), 55-60. https://www.sciencedirect.com/science/article/abs/pii/S0 376871699000125 (Accessed Nov 11, 2020).

[36] Lindhardt ,K.; Ravn, C.; Gizurarson, S.; Bechgaard, E. Intranasal absorption of buprenorphine--in vivo bioavailability study in sheep. Int. J. Pharm., 2000, 205(1-2), 159-163.

https://europepmc.org/article/med/11000552 (Accessed Nov 11, 2020).

[37] Kongstorp, M.; Bogen, I.L.; Stiris, T.; Andersen, J.M. High accumulation of methadone compared with buprenorphine in fetal rat brain after maternal exposure. J. Pharm. Exp. Ther. 2019, 371, 130-137.

https://pubmed.ncbi.nlm.nih.gov/31358559/ (Accessed Nov 11, 2020).

[38] Han, L.W.; Gao, C.; Mao, Q. An update on expression and function of p-gp/abcb1 and bcrp/abcg2 in the placenta and fetus. Expert Opin. Drug Metab. Toxicol., 2018; 14,817 -

https://pubmed.ncbi.nlm.nih.gov/30010462/ (Accessed Nov 11, 2020).

[39] Auvity, S.; Breuil, L.; Goislard, M.; Bottlaender, M.; Kuhnast, B.; Tournier, N.; Caillé, F. et al. An original radio-biomimetic approach to synthesize radiometabolites for PET imaging. Nucl. Med. Biol., 2020, 91:10-14.

https://www.sciencedirect.com/science/article/abs/pii/S0 969805120301888 (Accessed Nov 11, 2020).

[40] Liao, M.Z.; Gao, C.; Shireman, L.M.; Phillips, B.; Risler, L.J.; Neradugomma, N.K.; Choudhari, P.; Prasad, B.; Shen, D.D.; Mao, Q. P-gp/ABCBl exerts differential impacts on brain and fetal exposure to 
norbuprenorphine. Pharmacol. Res., 2017, 119, 61-71. https://www.ncbi.nlm.nih.gov/pmc/articles/PMC539244 2/ (Accessed Nov 11, 2020).

[41] Lindemalm, S.; Nydert, P.; Svensson, J.O.; Stahle, L.; Sarman, I. Transfer of buprenorphine into breast milk and calculation of infant drug dose. J. Human Lact. 2009, 25, 199. https://pubmed.ncbi.nlm.nih.gov/19136395/. (Accessed Nov 11, 2020).

[42] Katzung, B.G. Basic \& Clinical Pharmacology [Online]; 14ed.; McGraw-Hill: New York, 2018. https://accessmedicine.mhmedical.com/book.aspx?booki $\mathrm{d}=2249$ (Accessed Nov 10, 2020).

[43] Kenakin, T. Principles: receptor theory in pharmacology. Trends Pharmacol Sci. 2004, 25(4), 186-192. https://pubmed.ncbi.nlm.nih.gov/16139189/ (Accessed March 11, 2020).

[44] Kuo, A.; Magiera, J.; Rethwan, N.; Andersson, A.; Lam, A.L.; Wyse, B.; Meutermans, W.; Lewis, R.; Smith, M. In vitro profiling of opioid ligands using the cAMP formation assay and the beta-arrestin2 recruitment assay: no two ligands have the same profile. Eur. J. Pharmacol., 2020, 872, 1-10. https:/www.sciencedirect.com/science/article/abs/pii/S0 01429992030039X\#! (Accessed March 22, 2020).

[45] Dum, J.E. and Herz, A. In vivo receptor binding of the opiate partial agonist, buprenorphine, correlated with its agonistic and antagonistic actions. Br. J. Pharmacol., 1981, 74(3), 627-633. https://www.ncbi.nlm.nih.gov/pmc/articles/PMC207175 0/x (Accessed Jan 12, 2020).

[46] De Lean, A.; Stadel, J.M.; Lefkowitz, R.J.; A ternary complex model explains the agonist-specific binding properties of the adenylate cyclase-coupled betaadrenergic receptor. J. Biol. Chem., 1980, 255(15), 7108-7117. https://pubmed.ncbi.nlm.nih.gov/6248546/ (Accessed Nov 10, 2020).

[47] Tejwani, G.A. and Rattan, A.K. The role of spinal opioid receptors in antinociceptive effects produced by intrathecal administration of hydromorphone and buprenorphine in the rat. Anesth. Analg., 2002, 94(6), 1542-1546. https://pubmed.ncbi.nlm.nih.gov/12032023/ (Accessed Feb 26, 2020).

[48] Ding, Z.; Raffa, R.B. Identification of an additional supraspinal component to the analgesic mechanism of action of buprenorphine. Br. J. Pharmacol., 2009, 157(5), 831-843. https://www.ncbi.nlm.nih.gov/pmc/articles/PMC272126 7/ (Accessed Nov 10, 2020).
[49] Galandrin, S.; Oligny-Longpré, G.; Bouvier, M. The evasive nature of drug efficacy: implications for drug discovery. Trends Pharmacol. Sci., 2007, 28(8), 423430. https://pubmed.ncbi.nlm.nih.gov/15781180/ (Accessed Nov 10, 2020).

[50] Gladson, B.; Myslinski, M.; Streifer, M. Principles of pharmacology and selective agents in physical medicine and rehabilitation. In: Mitra, R. led. Principles of Rehabilitation Medicine [Online]; McGraw-Hill: New York, 2019.

https://accessmedicine.mhmedical.com/book.aspx?booki $\mathrm{d}=2550$ (Accessed Nov 10, 2020).

[51] Huang, P.; Kehner, G.B.; Cowan, A.; Liu-Chen, L.Y. Comparison of pharmacological activities of buprenorphine and norbuprenorphine: norbuprenorphine is a potent opioid agonist. J. Pharmacol. Exp. Ther., 2001, 297(2), 688-695.

https://pubmed.ncbi.nlm.nih.gov/11303059/ (Accessed Jan 9, 2020).

[52] Brown, S.M.; Campbell, S.D.; Crafford, A.; Regina, K.J.; Holtzman, M.J,; Kharasch, E.D. P-glycoprotein is a major determinant of norbuprenorphine brain exposure and antinociception. J. Pharmacol. Exp. Ther., 2012, 343, 53-61. (Accessed Nov 11, 2020).

[53] Butler, S. Buprenorphine-Clinically useful but often misunderstood. Scand. J. Pain, 2013, 4(3), 148-152. https://pubmed.ncbi.nlm.nih.gov/29913911/ (Accessed Mar. 19, 2020).

[54] Ohtani, M.; Kotaki, H.; Nishitateno, K.; Sawada, Y; Iga, T. Kinetics of respiratory depression in rats induced by buprenorphine and its metabolite,

norbuprenorphine. J. Pharmacol. Exp. Ther. 1997, 281(1), 428-433.

https://pubmed.ncbi.nlm.nih.gov/9103526/ (Accessed Jan 9, 2020).

[55] Dahan, A.; Yassen, A,; Bijl, H.; Romberg, R.; Sarton, E.; Teppema, L.; Olofsen, E.; Danhof, M. Comparison of the respiratory effects of intravenous buprenorphine and fentanyl in humans and rats. Br. J. Anaesth. 2005; 94(6), 825-834.

https://pubmed.ncbi.nlm.nih.gov/15833777/ (Accessed Jan 28, 2020).

1.

[56] Dahan A. Opioid-induced respiratory effects: new data on buprenorphine. Palliat. Med., 2006, 20, Suppl 1: s3s8. https://pubmed.ncbi.nlm.nih.gov/16764215/ (Accessed Jan 28, 2020).

[57] Ohtani, M.; Kotaki, H.; Sawada, Y.; Iga, T. Comparative analysis of buprenorphine- and norbuprenorphine-induced analgesic effects based on 
pharmacokinetic-pharmacodynamic modeling. $J$.

Pharmacol. Exp. Ther., 1995, 272(2), 505-510.

https://pubmed.ncbi.nlm.nih.gov/7853163/ (Accessed Jan 9, 2020).

[58] Coller, J.K.; Christrup, L.L.; Somogyi, A.A. Role of active metabolites in the use of opioids. Eur. J. Clin. Pharmacol., 2009, 65(2), 121-139.

https://pubmed.ncbi.nlm.nih.gov/18958460/ (Accessed Jan 9, 2020).

[59] Lutfy, K.; Eitan, S.; Bryant, C.D.; Yang, Y.C.; Saliminejad, N.; Walwyn, W.; Kieffer, B.L.; Takeshima, H.; Carroll, F.I.; Maidment, N.T.; Evans, C.J. 2003. Buprenorphine-in- duced antinociception is mediated by mu-opioid receptors and compromised by concomitant activation of opioid receptor-like receptors. J. Neurosci., 23, 10331-10337.

https://pubmed.ncbi.nlm.nih.gov/14614092/ (Accessed Nov 10, 2020).

[60] Lutfy, K.; Hossain, S.M.; Khaliq, I.; Maidment, N.T. Orphanin FQ/nociceptin attenuates the development of morphine tolerance in rats. Br. J. Pharmacol., 2001,134(3), 529-534. https://www.ncbi.nlm.nih.gov/pmc/articles/PMC157297 8/ (Accessed Jan 9, 2020).

[61] Brown, S.M.; Holtzman, M.; Kim, T.; Kharasch, E.D. Buprenorphine metabolites, buprenorphine-3glucuronide and norbuprenorphine-3-glucuronide, are biologically active. Anesthesiology, 2011, 115(6), 12511260.

https://www.ncbi.nlm.nih.gov/pmc/articles/PMC356093 5/ (Accessed Feb 26, 2020).

[62] Pergolizzi, J.; Böger, R.H.; Budd, K.; Dahan, A.; Erdine, S.; Hans, G.; Kress, H.; Langford, R.; Likar, R.; Raffa, R.B., Sacerdote, P. Opioids and the management of chronic severe pain in the elderly: consensus statement of an International Expert Panel with focus on the six clinically most often used World Health Organization Step III opioids (buprenorphine, fentanyl, hydromorphone, methadone, morphine, oxycodone). Pain Pract., 2008, 8(4), 287-313. https://pubmed.ncbi.nlm.nih.gov/18503626/ (Accessed Nov 10, 2020).

[63] Cremeans, C.M., Gruley, E., Kyle, D.J., Ko, M.C. Roles of mu-opioid receptors and nociceptin/orphanin FQ peptide receptors in buprenorphine-induced physiological responses in primates. J. Pharm. Exp. Ther., 2012, 343, 72-81. https://www.ncbi.nlm.nih.gov/pmc/articles/PMC346403 7/ (Accessed Nov 11, 2020).
[64] Kögel, B.; Christoph, T.; Strassburger, W.; Friderichs, E. Interaction of mu-opioid receptor agonists and antagonists with the analgesic effect of buprenorphine in mice. Eur J Pain, 2005, 9(5), 599611. https://pubmed.ncbi.nlm.nih.gov/16139189/ (Accessed Nov 10, 2020).

[65] Yassen, A.; Kan, J.; Olofsen, E.; Suidgeest, E.; Dahan, A.; Danhof, M. Mechanism-based pharmacokineticpharmacodynamic modeling of the respiratorydepressant effect of buprenorphine and fentanyl in rats. J. Pharmacol. Exp. Ther., 2006, 319(2), 682-692. https://www.ncbi.nlm.nih.gov/pmc/articles/PMC219033 6/ (Accessed Nov 10, 2020).

[66] Walsh, S.L.; Preston, K.L.; Stitzer, M.L.; Cone, E.J.; Bigelow, G.E. Clinical pharmacology of buprenorphine: ceiling effects at high doses. Clin. Pharmacol. Ther., 1994, 55(5), 569-580.

https://pubmed.ncbi.nlm.nih.gov/8181201/71 (Accessed Jan 9, 2020).

[67] Christoph, T.; Kögel, B.; Schiene, K.; Méen, M.; De Vry, J.; Friderichs, E. Broad analgesic profile of buprenorphine in rodent models of acute and chronic pain. Eur. J. Pharmacol., 2005; 507(1-3): 87-98. https://pubmed.ncbi.nlm.nih.gov/15659298/052 (Accessed Nov 10, 2020).

[68] Khanna, I.K. and Pillarisetti, S. Buprenorphine - an attractive opioid with underutilized potential in treatment of chronic pain. J. Pain Res., 2015, 8, 859870.

https://www.ncbi.nlm.nih.gov/pmc/articles/PMC467564 0/ (Accessed Nov 10, 2020).

[69] Sorge, J. and Sittl, R. Transdermal buprenorphine in the treatment of chronic pain: results of a phase III, multicenter, randomized, double-blind, placebocontrolled study. Clin Ther., 2004, 26(11), 1808-1820. https://pubmed.ncbi.nlm.nih.gov/15639693/ (Accessed Nov 10, 2020).

[70] Kress, H.G. Clinical update on the pharmacology, efficacy and safety of transdermal buprenorphine. Eur. J. Pain, 2008, 13(3), 219-230. https://pubmed.ncbi.nlm.nih.gov/18567516/ (Accessed Nov 10, 2020).

[71] Likar, R. Transdermal buprenorphine in the management of persistent pain - safety aspects. Ther. Clin. Risk Manag., 2006, 2(1),115-125. https://www.ncbi.nlm.nih.gov/pmc/articles/PMC166165 2/ (Accessed Nov 10, 2020).

[72] Gordon, A.; Callaghan, D.; Spink. D.; Cloutier, C.; Dzongowski, P.; O’Mahony, W.; Sinclair, D.; Rashiq, S; 
Buckley, N.; Cohen, G.; Kim, J.; Boulanger, A.; Piraino, P.S.; Eisenhoffer, J.; Harsanyi, Z.; Darke, A.C.; Michalko, K.J. Buprenorphine transdermal system in adults with chronic low back pain: a randomized, double-blind, placebo-controlled crossover study, followed by an open-label extension phase. Clin. Ther., 2010, 32(5), 844-860.

https://pubmed.ncbi.nlm.nih.gov/20685494/ (Accessed Feb 26, 2020).

[73] Steiner, D.; Munera, C.; Hale, M.; Ripa, S.; Landau, C. Efficacy and safety of buprenorphine transdermal system (BTDS) for chronic moderate to severe low back pain: a randomized, double-blind study. J. Pain., 2011, 12(11), 1163-1173.

https://pubmed.ncbi.nlm.nih.gov/21807566/ (Accessed Feb 26, 2020).

[74] Pace, M.C.; Passavanti, M.B.; Grella, E.; Mazzariello, L.; Maisto, M.; Barbarisi, M.; Baccari, E.; Sansone, P.; Aurilio, C. Buprenorphine in long-term control of chronic pain in cancer patients. Front. Biosci., 2007, 12, 1291-1299. https://pubmed.ncbi.nlm.nih.gov/17127381/ (Accessed Feb 26, 2020).

[75] Radbruch, L.; Vielvoye-Kerkmeer, A. Buprenorphine TDS: the clinical development rationale and results. Int. J. Clin. Pract. Suppl., 2003, 133, 15-24. https://pubmed.ncbi.nlm.nih.gov/12665119/ (Accessed Nov 10, 2020).

[76] Rauck, R.L.; Potts, J.; Xiang, Q.; Tzanis, E.; Finn, A. Efficacy and tolerability of buccal buprenorphine in opioid-naive patients with moderate to severe chronic low back pain. Postgrad Med., 2016, 128(1), 1-11. https://pubmed.ncbi.nlm.nih.gov/26634956/ (Accessed Feb 26, 2020).

[77] Gimbel, J.; Spierings, E.L.; Katz, N.; Xiang, Q.; Tzanis, E.; Finn, A. Efficacy and tolerability of buccal buprenorphine in opioid-experienced patients with moderate to severe chronic low back pain: results of a phase 3, enriched enrollment, randomized withdrawal study. Pain, 2016, 157(11), 2517-2526.

https://pubmed.ncbi.nlm.nih.gov/27434505/ (Accessed Nov 10, 2020).

[78] Hale, M.; Urdaneta, V.; Kirby, M.T.; Xiang, Q.; Rauck, R. Long-term safety and analgesic efficacy of buprenorphine buccal film in patients with moderate-tosevere chronic pain requiring around-the-clock opioids. J. Pain Res., 2017, 10, 233-240.. https://www.ncbi.nlm.nih.gov/pmc/articles/PMC527981 7/ (Accessed Feb 26, 2020).

[79] Pergolizzi, J.V.; Jr, Raffa, R.B. Safety and efficacy of the unique opioid buprenorphine for the treatment of chronic pain. J Pain Res. 2019, 12, 3299-3317.
https://www.ncbi.nlm.nih.gov/pmc/articles/PMC691754 5/ (Accessed Nov 10, 2020).

[80] Wallenstein, S.L.; Kaiko, R.F.; Rogers, A.G.; Houde, R.W. Crossover trials in clinical analgesic assays: studies of buprenorphine and morphine.

Pharmacotherapy, 1986, 6, 228-235. https://pubmed.ncbi.nlm.nih.gov/3540873/ (Accessed Nov 10, 2020).

[81] Edge, W.G.; Cooper, G.M.; Morgan, M. Analgesic effects of sublingual buprenorphine. Anaesthesia, 1979, 34(5), 463-467. https://associationofanaesthetistspublications.onlinelibrary.wiley.com/doi/pdf/ 10.1111/j.1365-2044.1979.tb06325.x (Accessed Nov 10, 2020).

[82] Sittl, R.; Likar, R.; Nautrup, B.P. Equipotent doses of transdermal fentanyl and transdermal buprenorphine in patients with cancer and noncancer pain: results of a retrospective cohort study. Clin. Ther., 2005, 27(2), 225-237. https://pubmed.ncbi.nlm.nih.gov/15811486/ (Accessed Nov 10, 2020).

[83] Risbo, A.; Jøosrgensen, B.C.; Kolby, P.; Pedersen, J.; Schmidt, J.F. Sublingual buprenorphine for premedication and postoperative pain relief in orthopaedic surgery. Acta Anaesthesiol. Scand., 1985, 29, 180-182. https://onlinelibrary.wiley.com/doi/abs/10.1111/j.13996576.1985.tb02181.x (Accessed Nov 10, 2020).

[84] Bullingham, R.; McQuay, H.; Moore, R.; Weir, L. An oral buprenorphine and paracetamol combination compared with paracetamol alone: a single dose double-blind postoperative study. Br. J. Clin.

Pharmacol.,1981, 12, 863-867. (Accessed Nov 10, 2020).

2.

[85] Wang, R.I.; Johnson, R.P.; Robinson, N.; Waite, E., the study of analgesics following single and repeated doses. J. Clin. Pharmacol., 1981, 21, 121-125. https://accp1.onlinelibrary.wiley.com/doi/abs/10.1002/j. 1552-4604.1981.tb01761.x (Accessed Nov 10, 2020).

3.

[86] Tigerstedt, I. and Tammisto, T., Double-blind, multiple-dose comparison of buprenorphine and morphine in postoperative pain, Acta Anaesthesiol. Scand., 1980, 24, 462-468.

https://pubmed.ncbi.nlm.nih.gov/7018155/ (Accessed Nov 10, 2020).

[87] Mok, M.S.; Lippmann, M.; Steen, S.N. Multidose/observational, comparative clinical analgetic evaluation of buprenorphine. J. Clin. Pharmacol., 1981, 21, 323-329. 
https://www.jpsmjournal.com/article/S0885-

3924(04)00566-4/fulltext (Accessed Nov 10, 2020).

[88] Kjaer, M.; Henriksen, H.; Knudsen, E.J. Intramuskulaer buprenorfin og morfin $\mathrm{i}$ behandlingen af cancersmerter. En kontrolleret undersøgelse [Intramuscular buprenorphine and morphine in the treatment of cancer pain. A controlled study]. Ugeskr Laeger. 1982, 144(18),1306-1309. (Accessed Nov 10, 2020).

[89] Cowan, A.; Doxey, J.C.; Harry, E.J. The animal pharmacology of buprenorphine, an oripavine analgesic agent. Br. J. Pharmacol., 1977, 60(4), 547-554. https://pubmed.ncbi.nlm.nih.gov/409449/ (Accessed Nov 10, 2020).

[90] Tröster, A.; Ihmsen, H.; Singler, B.; Filitz, J.; Koppert, W. Interaction of fentanyl and buprenorphine in an experimental model of pain and central sensitization in human volunteers. Clin. J. Pain., 2012, 28(8), 705-711. https://pubmed.ncbi.nlm.nih.gov/22469638/ (Accessed Nov 10, 2020).

[91] Beltrutti, D.; Niv, D.; Ben-Abraham, R.; Di Santo, S.; Weinbroum, A.A,; Late antinociception and lower untoward effects of concomitant intrathecal morphine and intravenous buprenorphine in humans. J. Clin. Anesth., 2002; 14(6), 441-446. https://pubmed.ncbi.nlm.nih.gov/12393113/ (Accessed Nov 10, 2020).

[92] Johnson, R.E.; Fudala, P.J.; Payne, R. Buprenorphine: considerations for pain management. J. Pain Symptom Manage., 2005, 29(3), 297-326.

https://pubmed.ncbi.nlm.nih.gov/15781180/ (Accessed Nov 10, 2020).

[93] Pharmacology. Katzung B.G.; Kruidering-Hall, M.; Trevor, A.J. Katzung \& Trevor's Pharmacology: Examination \& Board Review [Online]; 12ed McGrawHill: New York, 2019.

https://accessmedicine.mhmedical.com/book.aspx?booki $\mathrm{d}=2465$ (Accessed Nov 10, 2020)

[94] Gaveriaux-Ruff, C.; Nozaki, C.; Nadal, X,; Hever, C.V.; Weibel, R.; Matifas, A,; Filliol, D.; Nassar, A.M.; Wood, J.N;, Maldonado, R.; Kieffer, L.B. et al. Genetic ablation of delta opioid receptors in nociceptive sensory neurons increases chronic pain and abolishes opioid analgesia. Pain. 2011, 152(6), 1238-1248. https://pubmed.ncbi.nlm.nih.gov/21295407/ (Accessed March 11, 2020).

[95] Louis, F. (2006) Transdermal buprenorphine in pain management - experiences from clinical practice: five case studies. Int. J. Clin. Pract., 2006, 60, 1330-1334. https://pubmed.ncbi.nlm.nih.gov/16981980/ (Accessed Nov 10, 2020).

[96] Zhu, J.; Luo, L.Y.; Li, J.G.; Chen, C.; Liu-Chen L.Y. Activation of the cloned human kappa opioid receptor by agonists enhances [35S]GTPgammaS binding to membranes: determination of potencies and efficacies of ligands. J. Pharmacol. Exp. Ther. 1997, 282(2), 676684. http://intljpet.aspetjournals.org/cgi/content/abstract/282/2/676 (Accessed Nov 10, 2020).

[97] Romero, D.V.; Partilla, J.S.; Zheng, Q.X.; Heyliger, S.O.; Ni, Q.; Rice, K.C.; Lai, J.; Rothman, R.B. Opioid peptide receptor studies. 12. Buprenorphine is a potent and selective $\mu / \kappa$ antagonist in the $\left[{ }^{35} \mathrm{~S}\right]-\mathrm{GTP}-\gamma-\mathrm{S}$ functional binding assay. Synapse, 1999, 34, 83-94. https://pubmed.ncbi.nlm.nih.gov/10502307/ (Accessed Nov 10, 2020).

[98] Toll, L.; Berzetei-Gurske, I.P.; Polgar, W.E.; Brandt, S.R.; Adapa, I.D.; Rodriguez, L.; Schwartz, R.W., Haggart, D.; O’brien, A.; White, A.; Kennedy J.M.; Craymer, K.; Farrington, L.; Auh, J.S. Standard binding and functional assays related to medications development division testing for potential cocaine and opiate narcotic treatment medications. NIDA Res. Monogr., 1998, 178, 440-466. https://pubmed.ncbi.nlm.nih.gov/9686407/ (Accessed Nov 10, 2020).

[99] Rozenfeld, R.; Devi, L.A. Exploring a role for heteromerization in GPCR signaling specificity. Biochem. J., 2011; 433(1), 11-18. doi:10.1042/BJ20100458 (Accessed Nov 10, 2020).

[100] Yekkirala, A.S.; Banks, M.L.; Lunzer, M.M.; Negus, S.S.; Rice, K.C.; Portoghese, P.S. Clinically employed opioid analgesics produce antinociception via $\mu-\delta$ opioid receptor heteromers in rhesus monkeys. ACS Chem. Neurosci., 2012, 3(9), 720-727. https://pubs.acs.org/doi/abs/10.1021/cn300049m (Accessed Nov 10, 2020).

[101]Park, T.W.; Larochelle, M.R.; Saitz, R.; Wang, N.; Bernson, D.; Walley, A.Y. Associations between prescribed benzodiazepines, overdose death and buprenorphine discontinuation among people receiving buprenorphine. Addiction, 2019, 924-932. 115(5), https://onlinelibrary.wiley.com/doi/abs/10.1111/add.148 86 (Accessed Nov 10, 2020).

[102]Mello, N.K.; Bree, M.P.; Mendelson, J.H. Buprenorphine self-administration by rhesus monkey. Pharmacol. Biochem. Behav., 1981, 15, 215-225. https://www.sciencedirect.com/science/article/pii/00913 05781901805 (Accessed Nov 11, 2020). 
[103]Lukas, S.E.; Griffiths, R.R.; Bradley, J.V.; Buprenorphine self-administration by the baboon: Comparison with other opioids. NIDA Res. Monogr., 1983, 43, 178-83. https://pubmed.ncbi.nlm.nih.gov/6410250/ (Accessed Nov 11, 2020).

[104]Hubner, C.B. and Kornetsky, C. The reinforcing properties of the mixed agonist-antagonist buprenorphine as assessed by brain-stimulation reward. Pharmacol. Biochem. Behav., 1988, 30, 195-197. https://pubmed.ncbi.nlm.nih.gov/3174743/ (Accessed Nov 11, 2020).

[105]Wade, C.L.; Vendruscolo, L.F.; Schlosburg, J.E.; Hernandez, D.O.; Koob, G.F. Compulsive-like responding for opioid analgesics in rats with extended access. Neuropsychopharmacol., 2015, 40, 421-428. https://www.ncbi.nlm.nih.gov/pmc/articles/PMC444395 6/ (Accessed Nov 11, 2020).

[106]Gaiardi, M., Bartoletti, M., Bacchi, A., Gubellini, C., Babbini, M. Motivational properties of buprenorphine as assessed by place and taste conditioning in rats. Psychopharmacol, 1997, 130, 104-108. https://link.springer.com/article/10.1007/s00213005021 6 (Accessed Nov 11, 2020).

[107]Marquez, P.; Baliram, R.; Kieffer, B.L.; Lutty, K. The $\mathrm{mu}$ opioid receptor is involved in buprenorphineinduced locomotor stimulation and conditioned place preference. Neuropharmacol., 2007, 52, 1336-1341. https://www.ncbi.nlm.nih.gov/pmc/articles/PMC226790 1/ (Accessed Nov 11, 2020).

[108]Ma, L.L.; Freret, T.; Lange, M.; Bourgine, J.; Coquerel, A.; Lelong-Boulouard, V. Benzodiazepines increase the reward effects of buprenorphine in a conditioned place preference test in the mouse. Fund. Clin. Pharmacol., 2014, 28, 681-689.

https://pubmed.ncbi.nlm.nih.gov/24617653/ (Accessed Nov 11, 2020).

[109]Brown, E.E.; Finlay, J.M.; Wong, J.T.; Damsma, G.; Fibiger, H.C. Behavioral and neurochemical interactions between cocaine and buprenorphine: Implications for the pharmacotherapy of cocaine abuse. J. Pharmacol. Exp. Ther., 1991, 256(1), 119-26. (Accessed Nov 11, 2020).

[110]Hung, C.J.; Wu, C.C.; Chen, W.Y.; Chang, C.Y.; Kuan, Y.H.; Pan, H.C.; Liao, S.L.; Chen, C.J. Depression-like effect of prenatal buprenorphine exposure in rats. PLoS One, 2013, 8(12), e82262. https://pubmed.ncbi.nlm.nih.gov/24367510/. (Accessed Nov 11, 2020).
[111]Kintz, P. Deaths involving buprenorphine: A compendium of French cases. Forensic. Sci. Int., 2001, 121(1-2) 65-69.

https://pubmed.ncbi.nlm.nih.gov/11516889/ (Accessed Nov 11, 2020).

[112]Rege, S.V.; Ngo, D.A.; Ait-Daoud, N.; Holstege, C.P. Epidemiology of severe buprenorphine exposures reported to the U.S. Poison Centers. Drug Alcohol Depend., 2019, 202, 115-122. https://www.sciencedirect.com/science/article/abs/pii/S0 37687161930242X (Accessed Nov 11, 2020).

[113]Edwards, L.D. Buprenorphine in Wisconsin drivers: Concerns for impairment. J. Anal. Toxicol. 2019, 43, 644-650. https://pubmed.ncbi.nlm.nih.gov/31436286/ (Accessed Nov 11, 2020).

[114]Bunn. Erowid.org. Little bit goes a long way: An experience with buprenorphine (exp84031). 2011. erowid.org/exp/84031 (Accessed Nov 11, 2020).

[115]Zess. Erowid.org. (Accessed May 5, 2020), Quite nice, when I don't have anything else: An experience with buprenorphine with naloxone (Suboxone) (exp86906). erowid.org/exp/86906 (Accessed Nov 11, 2020).

[116]Blazes, C.K. and Morrow, J.D. Reconsidering the usefulness of adding naloxone to buprenorphine. Front. Psychiatry, 2020, 11, 549272.

https://www.frontiersin.org/articles/10.3389/fpsyt.2020. 549272/full (Accessed Nov 11, 2020).

[117]Hswen, Y.; Zhang, A.; Brownstein, J.S. Leveraging black-market street buprenorphine pricing to increase capacity to treat opioid addiction, 2010-2018. Prev. Med., 2020, 137, 106105.

https://pubmed.ncbi.nlm.nih.gov/32353575/ (Accessed Nov 11, 2020).

[118]Dasgupta, N.; Freifeld, C.; Brownstein, J.S.; Monone, C.M.; Surratt, H.L.; Poppich, L. et al. Crowdsourcing black market prices for prescription opioids. J. Med. Internet. Res., 2013, 15, 178.

https://pubmed.ncbi.nlm.nih.gov/23956042/ (Accessed Nov 11, 2020).

[119] Simpson, K.J.; Moran, M.T.; Foster, M.L.; Shah, D.T.; Chung, D.Y.; Nichols, S.D.; McCall, K.L.; Piper, B.J. Descriptive, observational study of pharmaceutical and nonpharmaceutical arrests, use, and overdoses in Maine. BMJ Open, 2019, 9, e027117.

https://bmjopen.bmj.com/content/9/4/e027117 (Accessed Nov 11, 2020).

[120] Orwin, J.M.; Orwin, J.; Price, M. A double-blind comparison of buprenorphine and morphine in conscious subjects following administration by the 
intramuscular route. Acta Anaesthesiol. Belg., 1976; 27(3): 171-181.

https://pubmed.ncbi.nlm.nih.gov/1032070/ (Accessed Nov 10, 2020).

[121]Budd, K. High dose buprenorphine for postoperative analgesia. Anesthesia, 1981, 36, 900-903.

https://associationofanaesthetistspublications.onlinelibrary.wiley.com/doi/pdf/10.1111/j.1 365-2044.1981.tb08867.x (Accessed Nov 11, 2020).

[122]Elkader, A.; Sproule, B. Buprenorphine clinical pharmacokinetics in the treatment of opioid dependence. Clin. Pharmacokinet., 2005, 44(7), 661-680. https://pubmed.ncbi.nlm.nih.gov/15966752/ (Accessed Nov 11, 2020).

[123] Gueye, P.N.; Borron, S.W.; Risède, P.; Monier, C.; Buneaux, F.; Debray, M.; Baud F.J. Buprenorphine and midazolam act in combination to depress respiration in rats. Toxicol. Sci., 2002, 65(1), 107-14. https://pubmed.ncbi.nlm.nih.gov/11752690/ (Accessed Nov 11, 2020).

[124] Gopal, S.; Tzeng, T.B.; Cowan, A. Characterization of the pharmacokinetics of buprenorphine and norbuprenorphine in rats after intravenous bolus administration of buprenorphine. Eur. J. Pharm. Sci., 2002,15(3), 287-293.

[125] Kintz, P. A new series of 13 buprenorphine-related deaths. Clin. Biochem., 2002, 35(7), 513-516. https://europepmc.org/article/med/12493578 (Accessed Nov 11, 2020).

[126] Mariottini. C.; Krukku, P.; Ojanpera, I. Concomitant drugs with buprenorphine user deaths. Drug Alcohol Depend., 2020, 108345 https://pubmed.ncbi.nlm.nih.gov/33127184/ (Accessed Nov 11, 2020).

[127]Wightman, R.S.; Perrone, J.; Scagos, R.; Krieger, M.; Nelson, L.S.; Marshall, B.D.L. Opioid overdose deaths with buprenorphine detected in postmortem toxicology: A retrospective analysis. J. Med.Tox., 2020. https://europepmc.org/article/med/32648229 (Accessed Nov 10, 2020).

[128]Pedapati, E.V. and Bateman, S.T. Toddlers requiring pediatric intensive care unit admission following athome exposure to buprenorphine/naloxone. Pediatric Crit. Care Med., 2011, 12(2), e1027.https://pubmed.ncbi.nlm.nih.gov/20921918/. (Accessed Nov 11, 2020).

[129]Hayes, B.D.; Klein-Schwartz, W.; Doyon, S. Toxicity of buprenorphine overdoses in children. Pediatrics,
2008, 121, 782-786.

https://pubmed.ncbi.nlm.nih.gov/18381506/ (Accessed Nov 11, 2020).

[130]Koren, G. and Nachmani, A. Drugs that can kill a toddler with one tablet or teaspoonful: A 2018 updated list. Clin. Drug Investig., 2019, 39, 217-220. https://pubmed.ncbi.nlm.nih.gov/30443871/ (Accessed Nov 11, 2020).

[131]Kim, H.K.; Smiddy, M.; Hoffman, R.S. et al. Buprenorphine may not be as safe as you think: a pediatric fatality from unintentional exposure. Pediatrics 2012, 130(6), e1700ee1703. https://pubmed.ncbi.nlm.nih.gov/23129079/ (Accessed Nov 11, 2020).

[132]Post, S.; Spiller, H.A.; Casavant, M.J.; Chounthirath, T.; Smith, G.A. Buprenorphine exposures among children and adolescents reported to US poison control centers. Pediatrics, 2018, 142(1), e20173652. https://pubmed.ncbi.nlm.nih.gov/29941678/ (Accessed Nov 13, 2020).

[133] Olkkola, K.T.; Leijala, M.A.; Maunuksela, E.L. Paediatric ventilato y effects of morphine andbuprenorphine revisited. Pediatric Anaesthesia 1995, 5, 303-305. https://onlinelibrary.wiley.com/doi/abs/10.1111/j.14609592.1995.tb00311.x (Accessed Nov 11, 2020).

[134] Schwartz, L.; Mercurio-Zappala, M.; Howland, M.A.; Hoffman, R.S.; Su, M.K. Unintentional methadone and buprenorphine exposures in children: developing prevention messages. J. Am. Pharm. Assoc. (2003), 2017, 57(2S), s83e6. https://pubmed.ncbi.nlm.nih.gov/28292505/ (Accessed Nov 11, 2020).

[135] Hampp, C.; Lovegrove, M.C.; Budnitz, D.S.; Mathew, J.; Ho, A.; McAninch, J. The role of unit-dose childresistant packaging in unintentional childhood exposures to buprenorphine-naloxone tablets. Drug Safety, 2020, 43, 189-191.

https://pubmed.ncbi.nlm.nih.gov/31745829/ (Accessed Nov 11, 2020).

[136] American College of Obstetricians and Gyncecologists. Opioid use and opioid use disorder in pregnancy committee opinion no. 711. Obstetrics Gyncol., 2017, 130, 81-94. https://www.acog.org/clinical/clinicalguidance/committee-opinion/articles/2017/08/opioiduse-and-opioid-use-disorder-in-pregnancy (Accessed Nov 11, 2020). 
[137]Chiadmi, F. and Shlatter, J. Buprenorphine and norbuprenorphine determination in mice plasma and brain by gas chromatography-mass spectrometry. Anal. Chem. Insights, 2014, 9, 9-16, https://www.ncbi.nlm.nih.gov/pmc/articles/PMC395685 9/ (Accessed Nov 11, 2020).

[138]Rudeck, J.; Vogl, S.; Heinl, C.; Steinfath, M.; Fritzwanker, S.; Kliewer, A.; Schulz, S., Schönfelder, G.; Bert, B. Analgesic treatment with buprenorphine should be adapted to the mouse strain. Pharmacol. Biochem. Behav., 2020, 191, 172877. https://pubmed.ncbi.nlm.nih.gov/32088361/ (Accessed Nov 11, 2020).

[139]Piper, B.J.; Meyer, J.S. Developmental neurotoxicology of abused drugs. In Reprod. Dev. Toxicol. (Ed R. Gupta), 2017, 413-428, http://dx.doi.org/10.1016/B978-0-12-804239-7.00023-8 (Accessed Nov 11, 2020).

[140]Kongstorp, M.; Bogen, I.L.; Stiris, T.; Andersen, J.M. Prenatal exposure to methadone or buprenorphine impairs cognitive performance in young adult rats. Drug Alcohol Depend., 2020, 212, 108008.

https://www.sciencedirect.com/science/article/pii/S0376 871620301733 (Accessed Nov 11, 2020).

[141] Sanchez, E.S.; Bigbee, J.W.; Fobbs, W.; Robinson, S.E.; Sato-Bigbee, C. Opioid addiction and pregnancy: Perinatal exposure to buprenorphine affects myelination in the developing brain. Glia, 2008, 56, 1017-1027. https://www.ncbi.nlm.nih.gov/pmc/articles/PMC257758 3/ (Accessed Nov 11, 2020).

[142]Wu, C.C.; Hung, C.J.; Shen, C.H.; Chen, W.Y.; Chang, C.Y.; Pan, H.C.; Liao, S.L.; Chen, C.J. Prenatal buprenorphine exposure decreases neurogenesis in rats. Toxicol. Lett., 2014, 225, 92-101. https://pubmed.ncbi.nlm.nih.gov/24321744/\#: :text=Thi s\%20study\%20provides\%20evidence\%20of,for\%2014 \%20days\%20and\%20a (Accessed Nov 11, 2020).

[143]Belcheva, M.M.; Dawn, S.; Barg, J.; McHale, R.J.; Ho, M.T.; Ignatova, E.; Coscia, C.J. Transient downregulation of neonatal rat brain opioid receptors upon in utero exposure to buprenorphine. Dev. Brain Research, 1994, 80, 158-162.

https://pubmed.ncbi.nlm.nih.gov/7955341/ (Accessed Jan 12, 2020).

[144]Anderson, J.M.; Hoiseth, G.; Nygaard, E. Prenatal exposure to methadone or buprenorphine: a meta- analysis. Early Hum., Dev., 2020, 143:104997

https://pubmed.ncbi.nlm.nih.gov/32146140/ (Accessed Nov 11, 2020).

[145]Wu, C.C.; Hung, C.J.; Lin, S.Y.; Wang, Y.Y.; Chang, C.Y.; Chen, W.Y.; Liao, S.L.; Raung, S.L.; Yang, C.P.; Chen, C.J. Treadmill exercise alleviated prenatal buprenorphine exposure induced depression in rats. Neurochem. Int., 2017, 110, 91-100. https://pubmed.ncbi.nlm.nih.gov/28962922/ (Accessed Nov 11, 2020).

[146] Wu, V.W.; Mo Q.; Yabe T.; Schwartz J.P.; Robinson S.E. Perinatal opioids reduce striatal nerve growth factor content in rat striatum. Eur. J. Pharmacol., 2001, 414, 211-214. https://europepmc.org/article/med/11239921 (Accessed Nov 10, 2020).

[147]Minozzi, S,; Amato, L.; Bellisario, C.; Ferri, M.; Davoli, M. Maintenance agonist treatments for opiatedependent pregnant women. Cochrane Database Syst. Rev., 2013, 12 ,

CD006318.https://www.cochrane.org/CD006318/ADDI CTN_maintenance-treatments-opiate-dependentpregnant-women (Accessed Nov 11, 2020).

[148] Chisolm, M.S.; Fitzsimons, H.; Leoutsakos, J.M.S.; Acquavita, S.P.; Hell, S.H.; Wilson-Murphy M.; Tuten, M.; Kaltenbach, K.; Martin, P.R.; Winklbaur, B.; Jansson, L.M.; Jones, H.E. A comparison of cigarette smoking profiles in opioid-dependent pregnant patients receiving methadone or buprenorphine. Nic. Tob. Res., 2013, 15, 1297-1304. https://pubmed.ncbi.nlm.nih.gov/23288871/ (Accessed Nov 11, 2020).

[149] Konijnenberg, C.; Melinder, A. Prenatal exposure to methadone and buprenorphine: A review of the potential effects on cognitive development. Child Neuropsychol., 2011, 17, 495-519. https://pubmed.ncbi.nlm.nih.gov/21480011/ (Accessed Nov 11, 2020).

[150] Wallin, C.M.; Bowen, S.E.; Roberge, C.L.; Richardson, L.M.; Brunnelte, S. Gestational buprenorphine exposure: Effects on pregnancy, development, neonatal opioid withdrawal syndrome, and behavior in a translational rodent model. Drug Alcohol Depend., 2019, 205, 107625.

https://pubmed.ncbi.nlm.nih.gov/31706250/ (Accessed Nov 11, 2020). 